Article

\title{
Field Comparison of Electrical Resistance, Electromagnetic Induction, and Frequency Domain Reflectometry for Soil Salinity Appraisal
}

\author{
Fernando Visconti *(i) and José Miguel de Paz ${ }^{\circledR}$ \\ Valencian Institute for Agricultural Research-IVIA (GV), Centre for Sustainable Agriculture \\ Development-CDAS, 46113 València, Spain; depaz_jos@gva.es \\ * Correspondence: visconti_fer@gva.es
}

Received: 10 September 2020; Accepted: 6 October 2020; Published: 13 October 2020

\begin{abstract}
By using different physical foundations and technologies, many probes have been developed for on-site soil salinity appraisal in the last forty years. In order to better understand their respective technical and practical advantages and constraints, comparisons among probes are needed. In this study, three different probes, based on electrical resistance (ER), electromagnetic induction (EMI), and frequency domain reflectometry (FDR), were compared during a field survey carried out in a large salt-threatened agricultural area. Information about the soil bulk electrical conductivity $\left(\sigma_{\mathrm{b}}\right)$ at different depths was obtained with each of the probes and, additionally, other soil properties were also measured depending on the specifications of each instrument and, moreover, determined in samples. On average, the EMI and FDR techniques could be regarded as equivalent for $\sigma_{\mathrm{b}}$ measurement, whereas ER gave higher $\sigma_{\mathrm{b}}$ values. Whatever the case, EMI, and also ER, had to be supplemented with information about soil clay, organic matter, and water mass fractions to attain, despite this effort, poor soil salinity estimations by means of multiple linear regression models $\left(R^{2}<0.5\right)$. On the contrary, FDR needed only probe data to achieve $R^{2}$ of 0.7 , though root mean standard error (RMSE) was still $1.5 \mathrm{dS} \mathrm{m}^{-1}$. The extra measurements and calculations that modern electrical conductivity contact probes integrate, specifically, those based on FDR, remarkably increase their ability for soil salinity appraisal, although there is still room for improvement.
\end{abstract}

Keywords: soil salinity; sensors; electromagnetic induction; frequency domain reflectometry; electrical resistance

\section{Introduction}

It has been estimated that nowadays soil salinity constrains agriculture in 10 to $25 \%$ of the irrigated lands globally [1-3]. Besides, the extension and intensity of salinization is expected to increase in the near future in low-lying areas as the sea-level rises [4], and in dry areas as the climate aridity strengthens [5]. In order to cope with this degradation process, it is necessary to count on reliable, but also fast, methods of soil salinity appraisal.

The electrical conductivity (EC) at $25^{\circ} \mathrm{C}$ of the soil saturated extract $\left(\sigma_{\mathrm{e}}\right)$ has been traditionally the standard measurement of soil salinity, and all the studies of crop tolerance to salinity referred to it [6-8]. However, the procedure of sampling and subsequent laboratory preparation of water-saturated soil-pastes is destructive and, moreover, time-consuming and laborious, and thus very expensive for data-intensive works. For this reason, several probes for the on-site measurement of the EC of the bulk soil, i.e., $\sigma_{\mathrm{b}}$, have been developed during the last forty years in order to estimate the $\sigma_{\mathrm{e}}$ from the $\sigma_{\mathrm{b}}$ value. However, the $\sigma_{\mathrm{b}}$ values result from the combination of several physicochemical soil properties, which include not only the soluble salts, but also the clay percentage and mineralogy, the water 
content, the organic matter content, the soil structure, and the temperature [9-14], thus complicating the prediction of $\sigma_{\mathrm{e}}$ from $\sigma_{\mathrm{b}}$.

Although some of the soil properties influencing $\sigma_{\mathrm{b}}$ have little importance for practical purposes, other such as the clay percentage and mineralogy have been found to be almost as influential as the soil salinity itself on the soil conductivity measurements taken, e.g., with the EM38 (unpublished results) and cannot be neglected. Therefore, site-specific calibration equations that relate $\sigma_{\mathrm{e}}$ to $\sigma_{\mathrm{b}}$ have been developed throughout the years to estimate the soil salinity in different types of soils [15-17]. Moreover, in addition to all the soil properties that influence $\sigma_{\mathrm{b}}$, different sensors respond differently to the same bulk soil. This occurs, first of all, because of the physical foundations in which the sensor is based, and second, because of the different soil volumes the sensor is sensitive to, in combination with the downward and lateral variability of soils [18]. Different sensing volumes are a logical consequence of the probe size, but also of its specific physical foundations and the working frequency of the electromagnetic fields it uses.

The first commercial devices that were used to measure $\sigma_{\mathrm{b}}$ were based on the measurement of the soil electrical resistance (ER) by means of four-electrode integrated probes [19]. Nowadays, the ER technique is still arguably the most widely used for $\sigma_{\mathrm{b}}$ measurement, mostly because it is used in the simplified two-electrode sensors that are integrated within the capacitance-conductance combined (CCC) probes [20-22]. Other sensors for $\sigma_{\mathrm{b}}$ measurement are based on reflectometry, remarkably in the time domain (TDR) $[12,23,24]$. Then, electromagnetic induction (EMI) is another important technique used in many instruments $[25,26]$, which notably does not need soil contact, and therefore is ideal for data-intensive works [27-30]. Finally, in more recent years the reflectometry technique has been expanded to the frequency domain with the development of frequency domain reflectometry (FDR) sensors for detection and reading of $\sigma_{\mathrm{b}}$ in addition to soil relative bulk dielectric permittivity $\left(\varepsilon_{\mathrm{b}}\right)$ [31-33].

The use of electrical conductivity probes offers a cost-effective way for soil salinity appraisal $[12,26]$. The rapid information obtained with these proximal probes can be readily used in a sustainable agriculture framework for monitoring and, eventually, for decision-making. Empirical or semi-empirical calibrations have been almost always used to estimate $\sigma_{\mathrm{e}}$ from $\sigma_{\mathrm{b}}$, and since the $\sigma_{\mathrm{b}}$ values obtained with the different available sensors are also different, not only site-specific, but also sensor-proprietary calibrations have been developed [20-22]. The calibrations have been developed mostly under laboratory conditions using sandy soils $[22,33,34]$. Besides, some comparisons between different techniques for $\sigma_{\mathrm{b}}$ measurement have been carried out, e.g., ER vs. TDR [22], TDR vs. FDR [35], ER vs. FDR [21], and EMI vs. TDR [18,36]. However, a comparison between more than two techniques, such as ER, EMI, and FDR, and for the appraisal of soil salinity in a large agricultural irrigated area of diverse soil texture has not been done up to date to the best of our knowledge. Comparisons of this kind are of the utmost interest for scientists and practitioners to help them choose among the different available options.

In the present work three commercial probes with different physical foundations, that is, electrical resistance (SCT-10), electromagnetic induction (EM38), and frequency domain reflectometry (WET-2) were compared for the measurement of $\sigma_{\mathrm{b}}$ and, eventually, for the estimation of salinity in terms of $\sigma_{\mathrm{e}}$ in an ample salt-threatened irrigated area in south-eastern Spain.

\section{Physical Basis of the Soil Electrical Conductivity Measurements}

Each probe used in this work has a different physical foundation to measure the soil electrical conductivity. Additionally, each one has a different sensing volume and, moreover, provides other supplementary measurements and calculations (Table 1). 
Table 1. Characteristics of the three probes used in this work to measure the soil electrical conductivity.

\begin{tabular}{|c|c|c|c|c|}
\hline $\begin{array}{l}\text { Probe } \\
\text { Model }\end{array}$ & $\begin{array}{c}\text { Physical Basis of the Electrical } \\
\text { Conductivity Measurement }\end{array}$ & $\begin{array}{l}\text { Sensing Volume } \\
\left(\mathrm{cm}^{3}\right)\end{array}$ & $\begin{array}{c}\text { Measured } \\
\text { Properties }\end{array}$ & $\begin{array}{l}\text { Calculated } \\
\text { Properties }^{+}\end{array}$ \\
\hline SCT-10 & Electrical Resistance & $2 \times 10^{3}$ & $\sigma_{\mathrm{b}}, T$ & $\sigma_{\mathrm{b}, 25}$ \\
\hline EM38 & Electromagnetic Induction & $10^{6}$ & $\sigma_{\mathrm{b}}^{*}$ & \\
\hline WET-2 & Frequency Domain Reflectometry & $5 \times 10^{2}$ & $\sigma_{\mathrm{b}}, \varepsilon_{\mathrm{b}}, T$ & $\theta_{\mathrm{w}}, \sigma_{\mathrm{p}}$ \\
\hline
\end{tabular}

${ }^{+} T$ : temperature; $\varepsilon_{\mathrm{b}}$ : Soil bulk dielectric permittivity; $\theta_{\mathrm{w}}$ : Soil water volumetric fraction; $\sigma_{\mathrm{b}}$ : Soil bulk electrical conductivity; $\sigma_{\mathrm{b}, 25}$; Soil bulk electrical conductivity at $25{ }^{\circ} \mathrm{C} ; \sigma_{\mathrm{b}}{ }^{*}$ : Depth-weighted soil electrical conductivity; $\sigma_{\mathrm{p}}$ : Soil pore water electrical conductivity.

\subsection{The Martek SCT-10}

The SCT-10 (Martek Instruments, Inc., Raleigh, NC, USA) is an ER compact four-electrode probe with a vertical configuration developed from the Wenner's array concept to be readily used in agriculture for continuous burial measurements and surveys [19,37]. In this probe a standard current $\left(I_{\mathrm{std}}\right)$ of $1 \mathrm{kHz}$ frequency $(f)$ is applied to the soil by means of the outer two electrodes. At this super low working frequency, the soil impedance is overwhelmingly contributed by the soil resistance, and therefore, the potential drop $(\Delta V)$ between the remaining inner electrodes results to be inversely proportional to the soil resistance like in a pure direct current measurement. Accordingly, a $\sigma_{\mathrm{b}}$ measurement related to $I_{\text {std }}$ and $\Delta V$ by Equation (1) is obtained:

$$
\sigma_{\mathrm{b}}=K \cdot I_{\mathrm{std}} / \Delta V
$$

In Equation (1), $k$ is the geometrical sensor parameter with units of reciprocal of length, which is known as the cell constant and assessed by calibration using a $\mathrm{KCl}$ conductivity standard aqueous solution. According to its specifications [38], the SCT-10 responds to a soil volume of roughly $2000 \mathrm{~cm}^{3}$ surrounding the probe. Additionally, the SCT-10 measures the soil temperature $(T)$ with a built-in thermistor and subsequently calculates the $\sigma_{\mathrm{b}}$ at the reference temperature of $25^{\circ} \mathrm{C}\left(\sigma_{\mathrm{b}, 25}\right)$ by using the following third order polynomial:

$$
\sigma_{\mathrm{b}, 25}=\sigma_{\mathrm{b}} \cdot\left(1.91-6.05 \cdot 10^{-2} \cdot T+1.22 \cdot 10^{-3} \cdot T^{2}-1.06 \cdot 10^{-5} \cdot T^{3}\right)
$$

Equation (2) is essentially equivalent to the ratio and exponential models developed for aqueous solutions [39], and its application gives an $\sigma_{\mathrm{b}, 25}$ value that can be more advantageously related to $\sigma_{\mathrm{e}}$ for practical interpretation.

Since resistance measurements depend on contact, in the usual practice an access hole with a slightly smaller diameter than the SCT-10 probe is drilled in the soil to ensure the best possible contact between all four electrodes and the soil.

Although the production of the SCT-10 was discontinued, the Eijkelkamp EC-probe (Eijkelkamp, Giesbeek, The Netherlands) is based on the same physical foundations and has a very similar design and working frequency $(0.45 \mathrm{kHz})$, being nowadays available from its manufacturer.

\subsection{The Geonics EM38}

The EM38 (Geonics Ltd., Mississauga, ON, Canada) is a compact two-coil EMI sensor that is mainly used for agricultural soil surveys. The transmitter coil (Tx) of the EM38 creates a primary oscillating magnetic field of $H_{\mathrm{p}}$ amplitude and $13.2 \mathrm{kHz}$ frequency that induces the formation of eddy currents within the soil. The receiver coil (Rx) of the EM38 responds to the secondary oscillating magnetic field of $H_{\mathrm{s}}$ amplitude induced, in turn, by the soil eddy currents. However, the Rx also directly responds to the primary field and therefore, the ratio of the quadrature-phase of $H_{\mathrm{s}}\left(H_{\mathrm{s}, \pi / 2}\right)$ to $H_{\mathrm{p}}$ is the quantity that is proportional to the soil conductivity. Accordingly, a depth-weighted $\sigma_{\mathrm{b}}$ 
average measurement, for which the siymbol $\sigma_{\mathrm{b}}{ }^{*}$ stands for, and which depends on the ratio $H_{\mathrm{s}, \pi / 2} / H_{\mathrm{p}}$, is obtained and shown to the user [40]:

$$
\sigma_{\mathrm{b}}{ }^{*}=4 \cdot\left(H_{\mathrm{s}, \pi / 2} / H_{\mathrm{p}}\right) /\left(\mu_{0} \cdot \omega \cdot \mathrm{s}^{2}\right)
$$

In Equation (3) $\mu_{0}$ is the vacuum magnetic permeability $\left(\mu_{0}=4 \cdot \pi \cdot 10^{-7} \mathrm{H} / \mathrm{m}\right), \omega$ is the angular frequency $(\omega=2 \cdot \pi \cdot f)$ and $\mathrm{s}$ is the separation between the coils, which is $1 \mathrm{~m}(s=1 \mathrm{~m})$ in the EM38. The measurement of a $\sigma_{\mathrm{b}}{ }^{*}$ value instead of a $\sigma_{\mathrm{b}}$ with the EMI sensors is a consequence of the fact that the distinct soil layers in which the soil can be conceptually split, contribute differently to the sensor signal. In the case of the EM38 two soil depth $(z)$ sensitivity functions were derived by McNeill [40] from an asymptotic approximation of the Maxwell's equations that hold for soils with low enough conductivity, i.e., featuring low induction numbers. Each of the sensitivity functions correspond to one of the two possible orientations in which the EM38 measurements can be taken: the vertical (Equation (4)) and the horizontal (Equation (5)):

$$
\begin{gathered}
\varphi_{\mathrm{V}}(z)=\frac{4 z}{\left(4 z^{2}+1\right)^{3 / 2}} \\
\varphi_{\mathrm{H}}(z)=2-\frac{4 z}{\left(4 z^{2}+1\right)^{1 / 2}}
\end{gathered}
$$

The main advantage of EMI probes compared to others is that they allow in-depth measurements, specifically down to $2 \mathrm{~m}$ with the EM38, without any soil contact [15]. This non-invasive technique presents, however, two drawbacks, which are the non-direct interpretation of the sensor reading, i.e., $\sigma_{\mathrm{b}}{ }^{*}$, and the nonlinear response at high soil conductivity. To overcome the first drawback, $\sigma_{\mathrm{b}}{ }^{*}$ measurements must be taken at both horizontal and vertical dipole orientations and at several heights over the ground. If, additionally, the soils are low-to-moderate in conductivity, the following linear relationship among the $\sigma_{\mathrm{b}}$ of up to $n$ soil layers and the $2 \times m \sigma_{\mathrm{b}}{ }^{*}$ measurements holds [41,42], and full advantage of the EMI technique can be taken:

$$
\left[\begin{array}{c}
\sigma_{b\left(\mathrm{~V} h_{1}\right)^{*}} \\
\sigma_{\mathrm{b}\left(\mathrm{V} h_{2}\right)^{*}} \\
\ldots \\
\sigma_{\mathrm{b}\left(\mathrm{V} h_{\mathrm{m}}\right)^{*}} \\
\sigma_{\mathrm{b}\left(\mathrm{H} h_{1}\right)^{*}} \\
\sigma_{\mathrm{b}\left(\mathrm{H} h_{2}\right)^{*}} \\
\ldots \\
\sigma_{\mathrm{b}\left(\mathrm{H} h_{\mathrm{m}}\right)^{*}}
\end{array}\right]=\left[\begin{array}{cccc}
\int_{0}^{d_{1}} \varphi_{\mathrm{V}}\left(z+h_{1}\right) \mathrm{d} z & \int_{d_{1}}^{d_{2}} \varphi_{\mathrm{V}}\left(z+h_{1}\right) \mathrm{d} z & \ldots & \int_{d_{n-1}}^{d_{n}} \varphi_{V}\left(z+h_{1}\right) \mathrm{d} z \\
\int_{0}^{d_{1}} \varphi_{\mathrm{V}}\left(z+h_{2}\right) \mathrm{d} z & \int_{d 1}^{d_{2}} \varphi_{\mathrm{V}}\left(z+h_{2}\right) \mathrm{d} z & \ldots & \int_{d_{n-1}}^{d_{n}} \varphi_{V}\left(z+h_{2}\right) \mathrm{d} z \\
\ldots & \ldots & \ldots & \ldots \\
\int_{0}^{d_{1}} \varphi_{\mathrm{V}}\left(z+h_{m}\right) \mathrm{d} z & \int_{d_{1}}^{d_{2}} \varphi_{\mathrm{V}}\left(z+h_{m}\right) \mathrm{d} z & \ldots & \int_{d_{n-1}}^{d_{n}} \varphi_{V}\left(z+h_{m}\right) \mathrm{d} z \\
\int_{0}^{d_{1}} \varphi_{\mathrm{H}}\left(z+h_{1}\right) \mathrm{d} z & \int_{d_{1}}^{d_{2}} \varphi_{\mathrm{H}}\left(z+h_{1}\right) \mathrm{d} z & \ldots & \int_{d_{n-1}}^{d_{n}} \varphi_{\mathrm{H}}\left(z+h_{1}\right) \mathrm{d} z \\
\int_{0}^{d_{1}} \varphi_{\mathrm{H}}\left(z+h_{2}\right) \mathrm{d} z & \int_{d_{1}}^{d_{2}} \varphi_{\mathrm{H}}\left(z+h_{2}\right) \mathrm{d} z & \ldots & \int_{d_{n-1}}^{n_{n}} \varphi_{\mathrm{H}}\left(z+h_{2}\right) \mathrm{d} z \\
\ldots & \ldots & \ldots & \ldots \\
\int_{0}^{d_{1}} \varphi_{\mathrm{H}}\left(z+h_{m}\right) \mathrm{d} z & \int_{d_{1}}^{d_{2}} \varphi_{\mathrm{H}}\left(z+h_{m}\right) \mathrm{d} z & \ldots & \int_{d_{n-1}}^{d_{n}} \varphi_{\mathrm{H}}\left(z+h_{m}\right) \mathrm{d} z
\end{array}\right]\left[\begin{array}{c}
\sigma_{\mathrm{b}\left(d_{1}\right)} \\
\sigma_{\mathrm{b}\left(d_{2}\right)} \\
\ldots \\
\sigma_{\mathrm{b}\left(d_{n}\right)}
\end{array}\right]
$$

The $n \sigma_{\mathrm{b}}$ values in which the soil can be split according to Equation (6) can be calculated from the $\sigma_{\mathrm{b}}{ }^{*}$ measurements by an inverse matrix multiplication.

\subsection{The Delta-T WET-2}

The WET-2 (Delta-T Devices Ltd., Burwell, Cambridge, UK) is an FDR compact light-weight two-electrode probe devised to be used for continuous burial measurements and surveys [43]. In this probe, a pulse current oscillating at $20 \mathrm{MHz}$ is applied to an RLC circuit that involves the soil as one capacitor, and the circuit settles at its resonant frequency, i.e., the frequency at which the current amplitude is maximum $\left(A_{\max }\right)$. At this relative low working frequency, the capacitor formed by the two electrodes and the soil in-between behaves as a lossy capacitor, i.e., as a capacitor that 
also conducts some electricity, and therefore, loses charge and energy to the surrounding medium. As a consequence, the soil impedance is contributed by both soil resistance and capacitance, and a $\sigma_{\mathrm{b}}$ measurement related to the amplitude at resonance is taken and shown to the user:

$$
\sigma_{\mathrm{b}}=k / R\left(A_{\max }\right)
$$

In Equation (7), $k$ is again the probe cell constant and $R\left(A_{\max }\right)$ stands for the amplitude-dependent resistance that features the RLC circuit at resonance. According to its specifications [43], the WET-2 responds to a soil volume of roughly $500 \mathrm{~cm}^{3}$ surrounding the probe electrodes. Besides, the WET-2 measures also the temperature by means of a thermistor at the central electrode tip. However, what is more remarkable about the WET-2 is that it also gets a measurement of the soil capacitance $(C)$ from the resonant frequency and hence the soil relative bulk dielectric permittivity $\left(\varepsilon_{\mathrm{b}}\right)$ is evaluated by means of the following equation:

$$
\varepsilon_{\mathrm{b}}=C\left(f_{\mathrm{res}}\right) / k
$$

where $k$ is again the geometrical probe factor with units of reciprocal of length, and $C\left(f_{\text {res }}\right)$ stands for the resonance-frequency-dependent capacitance. This way the WET-2 is moreover able to estimate the soil water content $\left(\theta_{\mathrm{w}}\right)$, specifically by means of the simplified dielectric mixing model that follows:

$$
\theta_{\mathrm{w}}=\left(-b_{0}+\varepsilon_{\mathrm{b}}^{1 / 2}\right) / b_{1}
$$

where $b_{0}$ and $b_{1}$ are two empirical coefficients that mainly depend on soil texture and organic matter. On the basis of the information given in the WET-2 user's manual [43], both coefficients can be estimated from the mass fractions of clay $\left(w_{\mathrm{c}}\right)$ and organic matter $\left(w_{\mathrm{om}}\right)$, provided these are known for the soil of interest:

$$
\begin{aligned}
& b_{0}=1.4+0.6\left(w_{\mathrm{c}}-w_{\mathrm{om}}\right) \\
& b_{1}=8.4+2.6\left(w_{\mathrm{c}}-w_{\mathrm{om}}\right)
\end{aligned}
$$

Besides $\theta_{\mathrm{w}}$, the WET-2 combines the $\sigma_{\mathrm{b}}, \varepsilon_{\mathrm{b}}$, and $T$ measurements using the following equation [31] to calculate the electrical conductivity in the soil pore water $\left(\sigma_{\mathrm{p}}\right)$, which is also shown to the user alongside $\theta_{\mathrm{w}}$ and the other measurements:

$$
\sigma_{\mathrm{p}}=\sigma_{\mathrm{b}} \cdot \varepsilon_{\mathrm{W}}(T) /\left(\varepsilon_{\mathrm{b}}-\varepsilon_{\sigma}=0\right)
$$

where $\varepsilon_{\mathrm{W}}(T)$ is the temperature-dependent soil water relative dielectric permittivity, for which the following equation for pure water is used [44]:

$$
\varepsilon_{\mathrm{W}}(T)=80.18-0.365 \cdot(T-20)
$$

Finally, $\varepsilon_{\sigma=0}$ in Equation (12) is the soil permittivity at zero conductivity, i.e., theoretically the permittivity of the dry soil or either the soil solids. This offset parameter can be found by calibration and in the WET-2 is taken equal to 4.1.

\section{Materials and Methods}

\subsection{Study Area}

The Vega Baja del Segura and Baix Vinalopó jointly constitute an area in south-eastern Spain with over 55,000 ha under irrigation (Figure 1). This area is salt-threatened because of the low quality of the irrigation waters, the aridity of the climate, and the limitations for land drainage [45]. 


\subsection{Survey Design}

A systematic-random sampling design was applied to the entire study area and used to gather a dataset of measurements and sampling agricultural irrigated sites that were representative, thus capturing the soil variability but avoiding bias [46]. Specifically, a total of 107 sites were selected for the measurement of the soil electrical conductivity with the probes SCT-10, EM38, and WET-2 (Figure 1). From these, 37 sites were also sampled, as is described in the following subsection (Figure 1).

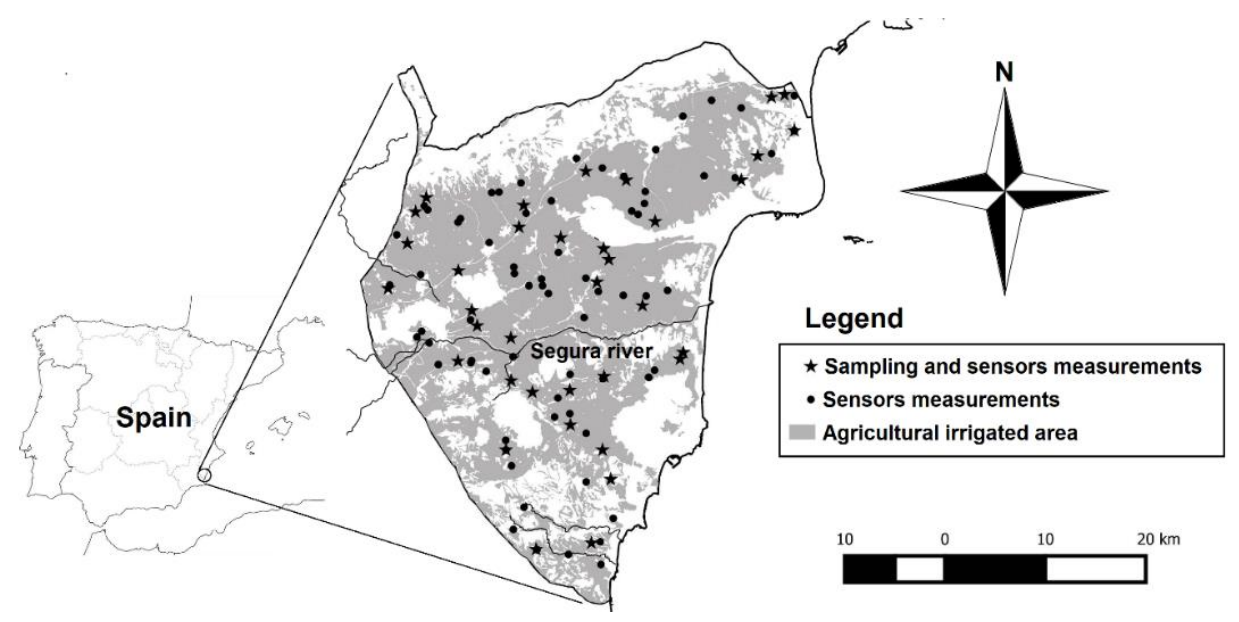

Figure 1. The study area of the Vega Baja del Segura and Baix Vinalopó with the location of the measurement and sampling sites.

\subsection{Soil Field Measurements and Sampling}

In each site, first of all, the EM38 was set up away from the target spot by leaving the instrument to warm-up in the shade for $15 \mathrm{~min}$, then by switching the $\mathrm{I} / \mathrm{P}$ and $\mathrm{Q} / \mathrm{P}$ controls to have a zero measurement with the instrument laying on a sufficiently large expanse of homogeneous low-conductive ground, e.g., the access road, and finally, by switching the $\mathrm{Q} / \mathrm{P}$ control to have a measurement in the vertical dipole mode double than in the horizontal one at $1.5 \mathrm{~m}$ height.

Once the EM38 setup was finished, the EM38 was taken to the exact target agricultural site and the $\sigma_{\mathrm{b}}{ }^{*}$ measurements were taken in the vertical and horizontal dipole orientations at five different heights over the ground: $0,50,100,150$, and $200 \mathrm{~cm}$.

Next, just below the center of the EM38, the WET-2 was used to take its corresponding $\sigma_{\mathrm{b}}, \varepsilon_{\mathrm{b}}$, and $T$ measurements at the soil surface $(0 \mathrm{~cm})$ and additionally, by drilling with a Riverside auger, at 10,30, and, either 50 or $60 \mathrm{~cm}$ depending on soil compactness. The extracted soil was separately collected from the 0-10, 10-30,30-65, and 65-95 depth intervals, saved in plastic bags, and carried to the laboratory.

Additionally, on a spot 1 to $2 \mathrm{~m}$ from the center of the EM38, another hole was drilled with another narrower auger and the SCT-10 measurements of $\sigma_{\mathrm{b}}$ and $T$ were taken at the following depths: 10, 30, 50, 60,70 , and $80 \mathrm{~cm}$ providing there was good enough contact between the probe electrodes and the soil.

\subsection{Soil Laboratory Determinations}

In the laboratory the soil samples were first of all analyzed for field water mass fraction $\left(w_{\mathrm{w}}\right)$ by weighing a representative subsample, oven-drying at $105^{\circ} \mathrm{C}$ for $24 \mathrm{~h}$, and weighing again. Then, the whole samples were spread out on trays, left to air-dry, and gently deaggregated to pass a 2-mm mesh sieve. The air-dried fine earths were then analyzed for hygroscopic water mass fraction $\left(w_{\mathrm{h}}\right)$, saturated paste water mass fraction $\left(w_{\mathrm{e}}\right)$, electrical conductivity at $25^{\circ} \mathrm{C}$ in the saturation extract $\left(\sigma_{\mathrm{e}}\right)$, clay mass fraction $\left(w_{\mathrm{c}}\right)$, and soil organic matter mass fraction $\left(w_{\mathrm{om}}\right)$ using the ensuing methods. 
The saturated soil pastes were prepared according to Rhoades [47], but using deionized water $\left(\sigma_{25} \approx 1 \mu \mathrm{S} / \mathrm{cm}\right)$ as the only reagent in the entire procedure, allowing the soil-water mixtures to equilibrate for approximately four hours and taking a subsample for $w_{\mathrm{e}}$ determination, which was done by means of oven-drying at $105{ }^{\circ} \mathrm{C}$ for $24 \mathrm{~h}$. Then, the saturation extract was obtained by suction with a vacuum system, and the $\sigma_{\mathrm{e}}$ was measured within one hour of extract collection with a microCM 2201 conductivity meter (Crison Instruments S.A., Barcelona, Spain) equipped with a conductivity cell of $1.1 \mathrm{~cm}^{-1}$ constant.

The clay, along with the silt and sand mass fractions according to the USDA, were determined using the Bouyoucos densimeter method [48]. The soil organic matter mass fraction was determined following the Walkley-Black procedure [49].

\subsection{Calculation of the $\sigma_{b}$ Values for the Sampled Soil Layers}

The $\sigma_{\mathrm{b}}$ and $T$ values of the four soil layers in which the soil was split for sampling, i.e., 0-10, 10-30, 30-65, and 65-95, were calculated from the probe measurements at the point soil depths at which these latter were made, as is explained in the following. These soil-depth-standardized $\sigma_{\mathfrak{b}}$ and $T$ values were then used for all the comparisons and models.

\subsubsection{From the Martek SCT-10 and Delta-T WET-2 $\sigma_{\mathrm{b}}$ Measurements}

In the case of the SCT-10 and WET-2 probes, the $\sigma_{\mathrm{b}}$ and $T$ values corresponding to the sampled soil depth intervals were calculated by linear interpolation, taking the mid depths of 5, 20, 47.5, and $80 \mathrm{~cm}$ for, respectively, the $0-10,10-30,30-65$, and 65-95 $\mathrm{cm}$ depth layers.

\subsubsection{From the Geonics EM $38 \sigma_{\mathrm{b}}{ }^{*}$ Measurements}

In the case of the EM38, the $\sigma_{\mathrm{b}}$ of the aforementioned layers in addition to the soil below $95 \mathrm{~cm}$ were assessed from the $\sigma_{\mathrm{b}}{ }^{*}$ measurements in both dipole orientations and heights over the ground by the inverse matrix multiplication of Equation (6). However, since all the $\sigma_{\mathrm{b}}{ }^{*}$ measurements were highly correlated, this inverse problem was computationally ill-defined and could not be addressed the simply way.

A Tikhonov regularization in which the minimum of the following target function $(\Phi)$ is searched trying different values of the $\lambda$ parameter has been found to satisfactorily sort out the aforementioned problem [41,42]:

$$
\Phi_{\mathrm{A}}=\sum_{i=1}^{2 m}\left(\sigma_{\mathrm{b}\left(\mathrm{X} h_{i}\right)} *-\sigma_{\mathrm{b}\left(\mathrm{X} h_{i}\right)} * \prime\right)^{2}+\lambda^{2} \sum_{j=1}^{n} \sum_{k=1}^{n}\left(l_{j k} \sigma_{\mathrm{b}\left(d_{k}\right)}\right)^{2}
$$

In Equation (14), X stands for $\mathrm{V}$ (vertical) or $\mathrm{H}$ (horizontal), $\sigma_{\mathrm{b}(\mathrm{Xhi})}{ }^{*}$ and $\sigma_{\mathrm{b}(\mathrm{Xhi})}{ }^{* \prime}$ are, respectively, the observed and predicted depth-weighted electrical conductivity in the $\mathrm{X}$ dipole mode at the $h_{i}$ height, and $l_{j k}$ is the element of the $j$ th row and $k$ th column of the following second derivative matrix L (Equation (15)):

$$
\mathbf{L}=\left[\begin{array}{ccccc}
-2 & 1 & 0 & \ldots & 0 \\
1 & -2 & 1 & \ldots & 0 \\
0 & 1 & -2 & \ldots & 0 \\
\ldots & \ldots & \ldots & \ldots & 1 \\
0 & 0 & 0 & 1 & -2
\end{array}\right]
$$

In this work different values of the $\lambda$ parameter within the range from 0 to 2 were used, and the value that featured the vertex of the L-shaped curve that arises when the first term on the right is graphed against the second one was selected as the most adequate for each site.

After the $\sigma_{\mathrm{b}}$ calculations were done, the hypothesis of low enough conductivity was checked through the calculation of the soil induction number $N_{\mathrm{B}}$

$$
N_{\mathrm{B}}=s \cdot\left(\mu_{0} \cdot \omega \cdot \sigma_{\mathrm{b} \_} \mathrm{m} / 2\right)^{1 / 2}
$$


where $\sigma_{\mathrm{b}_{-} \mathrm{m}}$ is the depth-average soil conductivity calculated according to:

$$
\sigma_{\mathrm{b} \_\mathrm{m}}=\left(\Sigma \sigma_{\mathrm{b}}\left(d_{j}\right) \cdot \Delta d_{j}\right) / \Sigma \Delta d_{j}
$$

where $\sigma_{\mathrm{b}}\left(d_{j}\right)$ and $\Delta d_{j}$ are, respectively, the $\sigma_{\mathrm{b}}$ and thickness of the $d j$ soil layer.

\subsection{Calculation of $\sigma_{b}$ at $25^{\circ} \mathrm{C}\left(\sigma_{b, 25}\right)$}

The SCT-10 calculates the bulk soil electrical conductivity at $25^{\circ} \mathrm{C}\left(\sigma_{\mathrm{b}, 25}\right)$ and offers this value to the user, however, the EM38 and the WET-2 do not. For these latter two probes, the $\sigma_{\mathrm{b}, 25}$ was calculated from $\sigma_{\mathrm{b}}$ by applying the same equation used by the SCT-10 (Equation (2)) along with the temperature measured by the WET-2.

\subsection{Data Analyses}

The values of $\sigma_{\mathrm{b}}$ obtained with each probe were pairwise compared, first graphically and then analytically, by testing the equality to zero of the mean standardized difference with the aid of the Student's $t$-test [50].

Next, the three probes were further compared by developing multiple linear regression (MLR) models in order to assess the $\sigma_{\mathrm{e}}$ from the $\sigma_{\mathrm{b}}$ measurements, additionally finding out whether the inclusion of other soil properties, either measured, calculated, or determined in the laboratory may improve the model's prediction ability. In order to know in which order these properties should be tried to be included in the corresponding MLR model, the Pearson's product moment correlation coefficients of $\sigma_{\mathrm{e}}$ with each property were calculated in advance for the sites and depths for which the specific probe measurements were available. Then, the MLR models were built, including one property at a time from the highest to the lowest correlation coefficient in absolute value. Every time one new property was included in the model, the equality to zero of its regression coefficient was tested using the Student's $t$-test. If the regression coefficient was different from zero at the $95 \%$ confidence level, the property was kept in the model, otherwise it was dropped. In this way, the ability of the probes to assess the $\sigma_{\mathrm{e}}$ was evaluated by means of the coefficients of determination, the root mean standard errors (RMSE), and the Lin's concordance correlation coefficients [51] of the MLR models, as well as the significance of the regression coefficients. All the statistical analyses were carried out with the $R$ software [52].

\section{Results}

\subsection{Soil Determinations}

The soils in the study area range in soil texture from silty clay to sandy loam with clay mass fractions from as low as $0.15 \mathrm{~g} \mathrm{~g}^{-1}$ to as high as $0.69 \mathrm{~g} \mathrm{~g}^{-1}$ with mean of $0.36 \pm 0.02 \mathrm{~g} \mathrm{~g}^{-1}$ with barely any differences among depths, while the soil organic matter mass fractions were found between 0.007 and $0.046 \mathrm{~g} \mathrm{~g}^{-1}$ with mean of $0.021 \pm 0.003 \mathrm{~g} \mathrm{~g}^{-1}$ in the topsoil (Table 2). The $\sigma_{\mathrm{e}}$ was between 0.72 and $13.8 \mathrm{dS} \mathrm{m}^{-1}$ with mean of $4.4 \pm 0.4 \mathrm{dS} \mathrm{m}^{-1}$, thus indicating that the area is salt-affected. The field water mass fraction was between 0.058 and $0.378 \mathrm{~g} \mathrm{~g}^{-1}$ with mean of $0.18 \pm 0.01 \mathrm{~g} \mathrm{~g}^{-1}$. Regarding the probability distributions of the soil properties, the Pearson's skewness coefficients were well over 1 for most of them, and thus they were positively skewed in general.

\subsection{Probe Measurements}

The $\sigma_{\mathrm{b}}$ measurements were between 0.03 and $6.00 \mathrm{dS} \mathrm{m}^{-1}$ with mean of $1.70 \pm 0.14 \mathrm{dS} \mathrm{m}^{-1}$ for the SCT-10 probe with distributions heavily positively skewed (Table 3), and between 0.06 and $4.00 \mathrm{dS} \mathrm{m}^{-1}$ with mean of $0.86 \pm 0.07 \mathrm{dS} \mathrm{m}^{-1}$ for the WET- 2 with distribution also very positively skewed (Table 4). The $\sigma_{\mathrm{b}}{ }^{*}$ measured with the EM38 on the soil surface were between 0.03 and $2.47 \mathrm{dS} \mathrm{m}^{-1}$ in the vertical dipole mode and between 0.05 and $2.21 \mathrm{dS} \mathrm{m}^{-1}$ in the horizontal one with data very positively skewed (Table 5). The $\sigma_{\mathrm{b}}{ }^{*}$ values systematically decreased as the instrument was lifted (Table 5). The $\sigma_{\mathrm{b}}$ data 
obtained from the EM38 $\sigma_{\mathrm{b}}{ }^{*}$ measurements by the inversion of Equation (6) were between 0.02 and $2.83 \mathrm{dS} \mathrm{m}^{-1}$ with mean of $0.71 \pm 0.04 \mathrm{dS} \mathrm{m}^{-1}$ (Table 6), and the corresponding induction numbers were between 0.012 and 0.101 with mean of $0.055 \pm 0.004$ (Table 6), which can be considered remarkably lower than the unity $\left(N_{\mathrm{B}}<<1\right)$. This gives support to the hypothesis of low-to-moderate conductivity of the soils of the study area and therefore, to the use of the linear model represented by Equation (6) for $\sigma_{\mathrm{b}}$ calculation. All the $\sigma_{\mathrm{b}}$ data calculated from the EM38 measurements presented very positively-skewed distributions in resemblance to the SCT-10 and WET- $2 \sigma_{\mathrm{b}}$ values.

Table 2. Statistical summary of the data on saturation extract electrical conductivity at $25^{\circ} \mathrm{C}\left(\sigma_{\mathrm{e}}\right)$ and field water $\left(w_{\mathrm{W}}\right)$, clay $\left(w_{\mathrm{c}}\right)$, and organic matter $\left(w_{\mathrm{om}}\right)$ mass fractions in the different sampled depth intervals.

\begin{tabular}{|c|c|c|c|c|}
\hline Depth Interval/cm & 0-10 & $10-30$ & $30-65$ & $65-95$ \\
\hline \multicolumn{5}{|l|}{$\sigma_{\mathrm{e}} / \mathrm{dS} \mathrm{m}^{-1}$} \\
\hline Count & 37 & 36 & 31 & 30 \\
\hline Mean & 4.34 & 3.88 & 4.77 & 4.58 \\
\hline Std. Dev. & 2.37 & 2.33 & 3.13 & 2.55 \\
\hline Maximum & 11.24 & 10.84 & 13.76 & 13.50 \\
\hline Minimum & 0.72 & 1.08 & 1.35 & 1.19 \\
\hline Skewness & 4.679 & 3.758 & 5.566 & 3.260 \\
\hline \multicolumn{5}{|l|}{$w_{\mathrm{w}} / \mathrm{g} \mathrm{g}^{-1}$} \\
\hline Count & 37 & 36 & 31 & 29 \\
\hline Mean & 0.180 & 0.183 & 0.190 & 0.184 \\
\hline Std. Dev. & 0.067 & 0.048 & 0.058 & 0.063 \\
\hline Maximum & 0.320 & 0.270 & 0.374 & 0.378 \\
\hline Minimum & 0.058 & 0.085 & 0.089 & 0.084 \\
\hline Skewness & 3.012 & -1.224 & 2.152 & -0.417 \\
\hline \multicolumn{5}{|l|}{$w_{\mathrm{c}} / \mathrm{g} \mathrm{g}^{-1}$} \\
\hline Count & 37 & 36 & 31 & 30 \\
\hline Mean & 0.354 & 0.363 & 0.359 & 0.381 \\
\hline Std. Dev. & 0.095 & 0.093 & 0.118 & 0.145 \\
\hline Maximum & 0.592 & 0.622 & 0.613 & 0.691 \\
\hline Minimum & 0.173 & 0.211 & 0.168 & 0.152 \\
\hline Skewness & 0.700 & 3.664 & 3.663 & 0.657 \\
\hline \multicolumn{5}{|l|}{$w_{\mathrm{om}} / \mathrm{g} \mathrm{g}^{-1}$} \\
\hline Count & 37 & 36 & 31 & 30 \\
\hline Mean & 0.021 & 0.012 & 0.008 & 0.006 \\
\hline Std. Dev. & 0.009 & 0.006 & 0.005 & 0.003 \\
\hline Maximum & 0.046 & 0.025 & 0.021 & 0.012 \\
\hline Minimum & 0.007 & 0.004 & 0.002 & 0.002 \\
\hline Skewness & 4.430 & 3.261 & 2.390 & 2.424 \\
\hline
\end{tabular}

Table 3. Statistical summary of the soil bulk electrical conductivity $\left(\sigma_{\mathrm{b}}\right)$ and temperature $(T)$ measurements taken in the study area with the SCT-10 at different depths.

\begin{tabular}{ccccccc}
\hline Depth/cm & $\mathbf{1 0}$ & $\mathbf{3 0}$ & $\mathbf{5 0}$ & $\mathbf{6 0}$ & $\mathbf{7 0}$ & $\mathbf{8 0}$ \\
\hline$\sigma_{\mathbf{b}} / \mathbf{d S ~ m}^{\mathbf{- 1}}$ & & & & & & \\
Count & 82 & 92 & 84 & 69 & 25 & 11 \\
Mean & 1.33 & 1.74 & 2.05 & 2.28 & 1.61 & 2.17 \\
Std. Dev. & 0.95 & 1.11 & 1.31 & 1.41 & 1.32 & 2.09 \\
Maximum & 4.98 & 4.83 & 5.97 & 6.05 & 6.40 & 7.59 \\
Minimum & 0.03 & 0.21 & 0.15 & 0.27 & 0.16 & 0.60 \\
Skewness & 6.856 & 8.301 & 8.721 & 10.747 & 3.632 & 3.841 \\
\hline T/ ${ }^{\circ} \mathbf{C}$ & & & & & & \\
Count & 82 & 92 & 84 & 69 & 25 & 11 \\
Mean & 31.6 & 29.7 & 28.8 & 28.0 & 27.2 & 26.5 \\
Std. Dev. & 3.7 & 3.3 & 3.0 & 2.9 & 2.6 & 2.0 \\
Maximum & 39.4 & 37.6 & 36.1 & 35.3 & 32.6 & 28.7 \\
Minimum & 22.4 & 22.6 & 22.1 & 21.8 & 22.4 & 22.6 \\
Skewness & 2.305 & 1.732 & 5.066 & 3.494 & 0.579 & 1.633 \\
\hline
\end{tabular}


Table 4. Statistical summary of the soil bulk electrical conductivity $\left(\sigma_{\mathrm{b}}\right)$, relative dielectric permittivity $\left(\varepsilon_{\mathrm{b}}\right)$, and temperature $(T)$ measurements taken in the study area with the WET-2 at different depths.

\begin{tabular}{ccccc}
\hline Depth/cm & $\mathbf{0}$ & $\mathbf{1 0}$ & $\mathbf{3 0}$ & $\mathbf{5 0}$ \\
\hline$\sigma_{\mathbf{b}} / \mathbf{d S ~ m}^{-\mathbf{1}}$ & & & & \\
Count & 103 & 104 & 99 & 67 \\
Mean & 0.67 & 0.80 & 0.96 & 1.13 \\
Std. Dev. & 0.62 & 0.49 & 0.61 & 0.70 \\
Maximum & 4.19 & 2.87 & 2.87 & 2.83 \\
Minimum & 0.04 & 0.09 & 0.14 & 0.13 \\
Skewness & 9.311 & 4.388 & 6.928 & 6.756 \\
\hline $\boldsymbol{E}_{\mathbf{b}}$ & & & & \\
Count & 103 & 104 & 99 & 67 \\
Mean & 23.90 & 26.59 & 27.76 & 27.60 \\
Std. Dev. & 9.34 & 7.66 & 8.68 & 8.66 \\
Maximum & 55.59 & 42.81 & 46.94 & 45.14 \\
Minimum & 8.11 & 9.61 & 12.69 & 11.73 \\
Skewness & 3.349 & 0.651 & -0.744 & 0.590 \\
\hline T/ ${ }^{\circ} \mathbf{C}$ & & & & \\
Count & 103 & 104 & 99 & 67 \\
Mean & 28.91 & 26.57 & 25.80 & 25.18 \\
Std. Dev. & 3.76 & 2.59 & 2.29 & 2.44 \\
Maximum & 38.00 & 32.60 & 32.20 & 30.30 \\
Minimum & 20.80 & 20.70 & 20.60 & 20.70 \\
Skewness & 3.326 & 0.817 & -2.578 & -0.180 \\
\hline
\end{tabular}

Table 5. Statistical summary of the soil depth-weighted electrical conductivity measurements taken in the study area with the EM38 in the vertical $\left(\sigma_{\mathrm{bV}}{ }^{*}\right)$ and horizontal $\left(\sigma_{\mathrm{bH}}{ }^{*}\right)$ dipole modes at different heights.

\begin{tabular}{cccccc}
\hline Height/cm & $\mathbf{0}$ & $\mathbf{5 0}$ & $\mathbf{1 0 0}$ & $\mathbf{1 5 0}$ & $\mathbf{2 0 0}$ \\
\hline$\sigma_{\mathbf{b v}^{*} / \mathbf{d S ~ m}^{-\mathbf{1}}}$ & & & & & \\
Count & 107 & 107 & 107 & 107 & 107 \\
Mean & 0.79 & 0.44 & 0.30 & 0.22 & 0.16 \\
Std. Dev. & 0.55 & 0.29 & 0.19 & 0.14 & 0.09 \\
Maximum & 2.47 & 1.31 & 0.90 & 0.57 & 0.40 \\
Minimum & 0.03 & 0.01 & 0.01 & 0.00 & 0.00 \\
Skewness & 7.555 & 8.965 & 8.093 & 7.045 & 5.457 \\
\hline$\sigma_{\text {bH }}{ }^{*} / \mathbf{d S ~ ~ m ^ { - 1 }}$ & & & & & \\
Count & 107 & 107 & 107 & 107 & 107 \\
Mean & 0.70 & 0.22 & 0.15 & 0.10 & 0.08 \\
Std. Dev. & 0.44 & 0.14 & 0.09 & 0.07 & 0.05 \\
Maximum & 2.21 & 0.62 & 0.41 & 0.28 & 0.20 \\
Minimum & 0.05 & 0.00 & -0.03 & -0.04 & -0.05 \\
Skewness & 9.148 & 6.785 & 8.664 & 6.546 & 5.000 \\
\hline
\end{tabular}

Table 6. Statistical summary of the soil bulk electrical conductivity at different soil depth intervals estimated by inversion of Equation (6) in the soils of the study area using the Tikhonov regularization and the induction numbers $\left(N_{\mathrm{B}}\right)$ calculated using Equation (16).

\begin{tabular}{|c|c|c|c|c|c|c|}
\hline Depth Interval/cm & 0-10 & $10-30$ & $30-65$ & $65-95$ & $>95$ & $\mathbf{N}_{\mathbf{B}}$ \\
\hline \multicolumn{7}{|l|}{$\sigma_{\mathrm{b}} / \mathrm{dS} \mathrm{m}^{-1}$} \\
\hline Count & 107 & 107 & 107 & 107 & 107 & 107 \\
\hline Mean & 0.43 & 0.78 & 0.95 & 0.87 & 0.54 & 0.055 \\
\hline Std. Dev. & 0.27 & 0.50 & 0.62 & 0.57 & 0.36 & 0.019 \\
\hline Maximum & 1.36 & 2.40 & 2.83 & 2.57 & 1.61 & 0.101 \\
\hline Minimum & 0.02 & 0.04 & 0.04 & 0.04 & 0.02 & 0.012 \\
\hline Skewness & 8.445 & 9.031 & 9.367 & 9.166 & 8.349 & 4.280 \\
\hline
\end{tabular}

Regarding the rest of the probe measurements, the temperature registered with the SCT-10 was between 21.0 and $39.3^{\circ} \mathrm{C}$ with mean of $30.0 \pm 0.4{ }^{\circ} \mathrm{C}$, while the WET-2 measured temperatures were 
between 20.7 and 37.2 with mean of $26.9 \pm 0.4{ }^{\circ} \mathrm{C}$. The soil relative bulk dielectric permittivity was only measured with the WET-2 and was between 9.0 and 53.6 with mean of $26 \pm 1$.

\subsection{Comparison of $\sigma_{b}$ Values}

The EM38 $\sigma_{\mathrm{b}}$ calculated data was, with $r=0.73$, remarkably correlated with the WET-2 $\sigma_{\mathrm{b}}$ measurements (Figure 2a). Besides, in spite of the wide range of differences between the EM38 and the WET-2 measurements, which was $4.0 \mathrm{dS} / \mathrm{m}$, the mean difference was only $-0.13 \mathrm{dS} / \mathrm{m}$. However, according to the test of the normalized difference, this value, though small, was significantly different from zero $(p<0.001)$, which indicates that the EM38 gave, on average, slightly lower $\sigma_{\mathrm{b}}$ values than the WET-2.
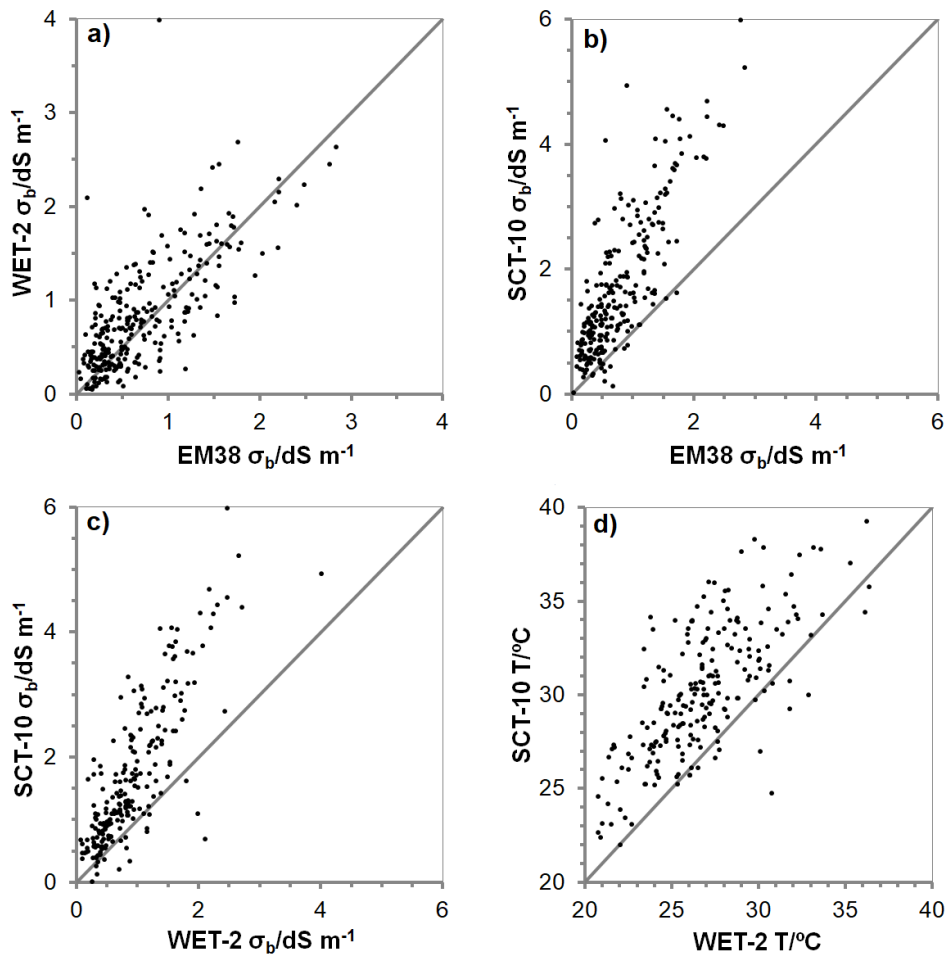

Figure 2. Comparison for all the sites and sampled soil layers $(0-10,10-30,30-65$, and $65-95 \mathrm{~cm})$ of the soil bulk electrical conductivity $\left(\sigma_{\mathrm{b}}\right)$ values calculated from the EM38 data and measured with the WET-2 and the SCT-10: (a) WET-2 vs. EM38 $\sigma_{\mathrm{b}}$ values, (b) SCT-10 vs. EM38 $\sigma_{\mathrm{b}}$ values, and (c) SCT-10 vs. WET-2 $\sigma_{\mathrm{b}}$ values, as well as (d) the temperature values measured with the WET-2 and SCT-10.

Regarding the SCT-10, even though its $\sigma_{\mathrm{b}}$ measurement exhibited even higher correlation with either the EM38 or the WET- $2 \sigma_{\mathrm{b}}$, i.e., respectively, $r=0.83$ and $r=0.82$, it was on average much higher than whichever of them, specifically, $0.94 \mathrm{dS} / \mathrm{m}$ higher than the EM38 $\sigma_{\mathrm{b}}$ and $0.81 \mathrm{dS} / \mathrm{m}$ higher than the WET-2 $\sigma_{\mathrm{b}}$ (Figure $2 \mathrm{~b}, \mathrm{c}$ ). This disagreement was observed even in the temperature, with the SCT-10 consistently measuring higher than the WET-2, specifically, $3.4^{\circ} \mathrm{C}$ more on average (Figure $2 \mathrm{~d}$ ).

\subsection{Development of Models for $\sigma_{e}$ Estimation}

\subsubsection{The Martek SCT-10}

With a correlation coefficient of 0.55 the property correlated the most with the $\sigma_{\mathrm{e}}$ was the $\sigma_{\mathrm{b}}$. This was followed by temperature, the organic matter, the clay, and the field water mass fractions (Table 7). Interestingly, the correlation of $\sigma_{\mathrm{e}}$ dropped to 0.52 when the temperature-standardized $\sigma_{\mathrm{b}, 25}$ was used instead of $\sigma_{\mathrm{b}}$. 
Table 7. Pearson's product-moment correlation coefficients among the SCT-10 probe measurements and calculations and soil properties in the sites and depths the former were available.

\begin{tabular}{ccccccc}
\hline & $\sigma_{\mathbf{b}}$ & $T$ & $\sigma_{\mathbf{b}, 25}$ & $\sigma_{\mathbf{e}}$ & $w_{\mathbf{w}}$ & $w_{\mathbf{c}}$ \\
\hline$T$ & 0.053 & & & & & \\
$\sigma_{\mathbf{b}, 25}$ & 0.994 & -0.022 & & & & \\
$\sigma_{\mathbf{e}}$ & 0.548 & 0.144 & 0.521 & & & \\
$w_{\mathbf{w}}$ & 0.564 & -0.172 & 0.567 & 0.041 & & \\
$w_{\mathbf{c}}$ & 0.320 & 0.197 & 0.307 & -0.054 & 0.310 & \\
$w_{\text {om }}$ & -0.004 & 0.345 & -0.040 & 0.132 & 0.092 & 0.312 \\
\hline
\end{tabular}

According to the order of the correlation coefficients, the properties $\sigma_{\mathrm{b}}, T, w_{\mathrm{om}}, w_{\mathrm{c}}$, and $w_{\mathrm{w}}$ were tried to be included following this succession in an increasingly complex MLR for $\sigma_{\mathrm{e}}$ estimation with the SCT-10 probe. The simple linear regression model using $\sigma_{\mathrm{b}}$ explained $30 \%$ of variance (Table 8, model number 1). The inclusion of either the temperature or the organic matter content barely increased $\mathrm{R}^{2}$. The regression coefficients of both were not either different from zero at the 95\% confidence level and therefore, they were eventually not included in the model for $\sigma_{\mathrm{e}}$ estimation (Table 8, model numbers 2 and 3). On the contrary the inclusion of the clay mass fraction and the field water mass fraction did increase $\mathrm{R}^{2}$ and moreover, their regression coefficients were different from zero at the $95 \%$ level, thus being eventually kept in a model of the form: $\sigma_{\mathrm{e}}=\mathrm{a} \sigma_{\mathrm{b}}+\mathrm{b} w_{\mathrm{c}}+\mathrm{c} w_{\mathrm{w}}$ (Table 8, model numbers 4 and 5). This last model explained $44 \%$ of the variance in the $\sigma_{\mathrm{e}}$ data and had RMSE of $1.8 \mathrm{dS} \mathrm{m}^{-1}(44 \%)$. The fit between predictions and measurements of $\sigma_{\mathrm{e}}$ according to model 5 can be appreciated in Figure 3a, with an associated Lin's concordance correlation coefficient equal to 0.61.
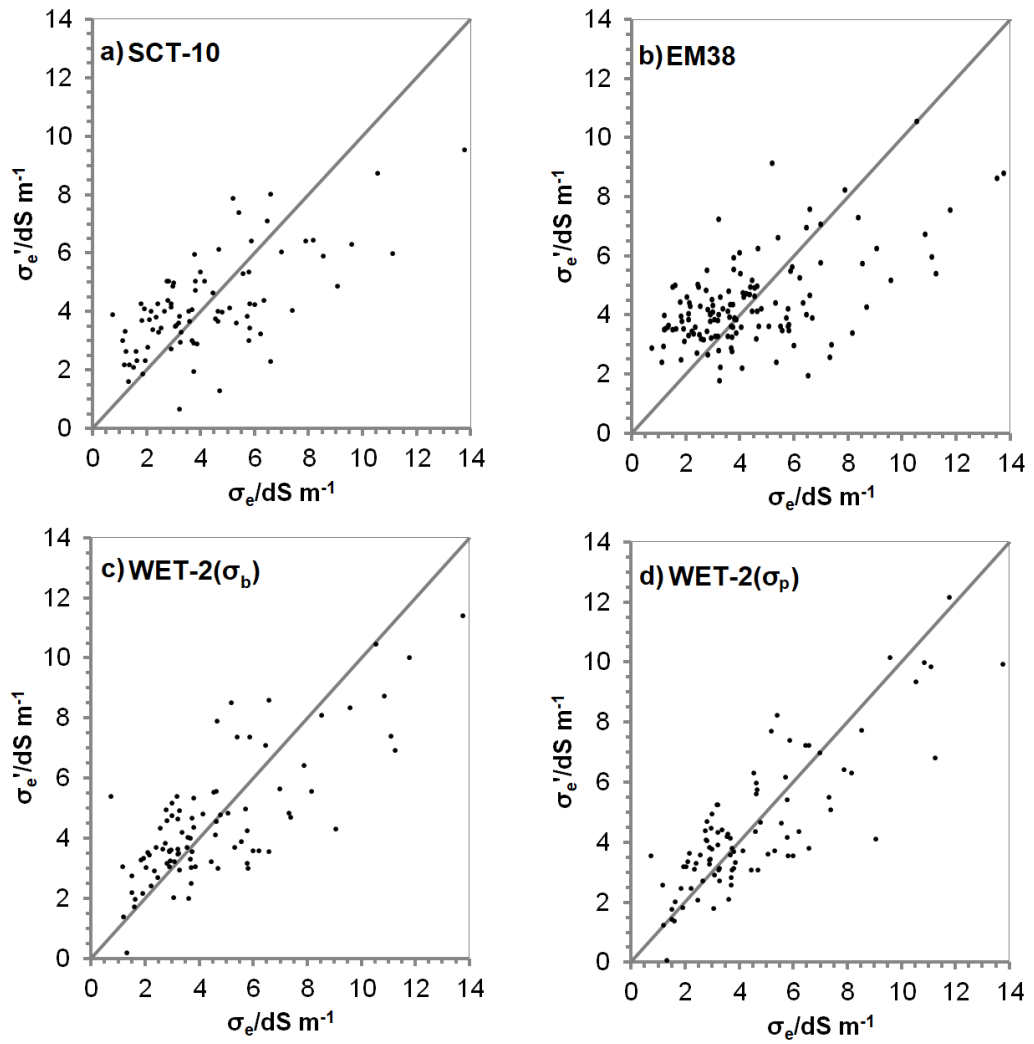

Figure 3. Predictions of electrical conductivity at $25^{\circ} \mathrm{C}$ in the saturation extract made with the best most parsimonious models developed for each probe $\left(\sigma_{\mathrm{e}}{ }^{\prime}\right)$ against measurements $\left(\sigma_{\mathrm{e}}\right)$ : (a) SCT-10 (Table 8 , model number 5), (b) EM38 (Table 8, model number 9), (c) WET-2 ( $\left.\sigma_{\mathrm{b}}\right)$ (Table 8, model number 12$)$ and (d) WET-2 $\left(\sigma_{\mathfrak{p}}\right)$ (not shown in Table 8 ). 
Table 8. Coefficients of determination and regression along with their standard errors, student's $t$ and $p$ values for the different multiple linear regression models developed to estimate the saturation extract electrical conductivity at $25^{\circ} \mathrm{C}\left(\sigma_{\mathrm{e}}\right)$, where the best most parsimonious model for each probe has been highlighted in italics.

\begin{tabular}{|c|c|c|c|c|c|c|c|c|c|}
\hline Model Number & Probe & $\mathrm{R}^{2}$ & Regress. Coeff. & $\sigma_{\mathbf{b}}$ & $\varepsilon_{b}^{1 / 2}$ & $T$ & $w_{\mathrm{w}}$ & $w_{\mathrm{c}}$ & $w_{\text {om }}$ \\
\hline \multirow{4}{*}{1} & \multirow{4}{*}{ SCT-10 } & \multirow{4}{*}{0.300} & Value & 1.19 & - & - & - & - & - \\
\hline & & & Std. Dev. & 0.20 & - & - & - & - & - \\
\hline & & & $t$ & 5.96 & - & - & - & - & - \\
\hline & & & $p$ & $<0.001$ & - & - & - & - & - \\
\hline \multirow{4}{*}{2} & \multirow{4}{*}{ SCT-10 } & \multirow{4}{*}{0.326} & Value & 1.20 & - & 0.12 & - & - & - \\
\hline & & & Std. Dev. & 0.20 & - & 0.06 & - & - & - \\
\hline & & & $t$ & 6.10 & - & 1.79 & - & - & - \\
\hline & & & $p$ & $<0.001$ & - & 0.078 & - & - & - \\
\hline \multirow{4}{*}{3} & \multirow{4}{*}{ SCT-10 } & \multirow{4}{*}{0.318} & Value & 1.19 & - & - & - & - & 40.95 \\
\hline & & & Std. Dev. & 0.20 & - & - & - & - & 27.88 \\
\hline & & & $t$ & 6.01 & - & - & - & - & 1.47 \\
\hline & & & $p$ & $<0.001$ & - & - & - & - & 0.146 \\
\hline \multirow{4}{*}{4} & \multirow{4}{*}{ SCT-10 } & \multirow{4}{*}{0.359} & Value & 1.37 & - & - & - & -6.00 & - \\
\hline & & & Std. Dev. & 0.20 & - & - & - & 2.20 & - \\
\hline & & & t & 6.74 & - & - & - & -2.73 & - \\
\hline & & & $p$ & $<0.001$ & - & - & - & 0.008 & - \\
\hline \multirow{4}{*}{5} & \multirow{4}{*}{ SCT-10 } & \multirow{4}{*}{0.441} & Value & 1.77 & - & - & -15.10 & -4.80 & - \\
\hline & & & Std. Dev. & 0.22 & - & - & 4.36 & 2.09 & - \\
\hline & & & $t$ & 7.94 & - & - & -3.46 & -2.30 & - \\
\hline & & & $p$ & $<0.001$ & - & - & $<0.001$ & 0.024 & - \\
\hline \multirow{4}{*}{6} & & & Value & 2.00 & - & - & - & - & - \\
\hline & & & Std. Dev. & 0.34 & - & - & - & - & - \\
\hline & EM38 & 0.203 & $t$ & 5.81 & - & - & - & - & - \\
\hline & & & $p$ & $<0.001$ & - & - & - & - & - \\
\hline & & & Value & 2.00 & - & - & 0.00006 & - & - \\
\hline & & & Std. Dev. & 0.35 & - & - & 0.02386 & - & - \\
\hline 7 & EM38 & 0.203 & $t$ & 5.67 & - & - & 0.00272 & - & - \\
\hline & & & $p$ & $<0.001$ & - & - & 0.998 & - & - \\
\hline & & & Value & 2.97 & - & - & - & -9.10 & - \\
\hline 8 & FM38 & 0310 & Std. Dev. & 0.39 & - & - & - & 2.02 & - \\
\hline 8 & EM38 & 0.310 & $t$ & 7.67 & - & - & - & -4.50 & - \\
\hline & & & $p$ & $<0.001$ & - & - & - & $<0.001$ & - \\
\hline & & & Value & 3.20 & - & - & - & -10.58 & 54.36 \\
\hline 9 & & & Std. Dev. & 0.39 & - & - & - & 2.10 & 23.84 \\
\hline 9 & EM38 & 0.336 & $t$ & 8.11 & - & - & - & -5.05 & 2.28 \\
\hline & & & $p$ & $<0.001$ & - & - & - & $<0.001$ & 0.024 \\
\hline & & & Value & 2.46 & - & - & - & - & - \\
\hline & & & Std. Dev. & 0.39 & - & - & - & - & - \\
\hline 10 & WET-2 & 0.303 & $t$ & 6.22 & - & - & - & - & - \\
\hline & & & $p$ & $<0.001$ & - & - & - & - & - \\
\hline & & & Value & 5.53 & -2.56 & - & - & - & - \\
\hline & & & Std. Dev. & 0.59 & 0.41 & - & - & - & - \\
\hline 11 & WET-2 & 0.518 & $t$ & 9.34 & -6.26 & - & - & - & - \\
\hline & & & $p$ & $<0.001$ & $<0.001$ & - & - & - & - \\
\hline & & & Value & 5.71 & -2.51 & 0.23 & - & - & - \\
\hline & & & Std. Dev. & 0.55 & 0.38 & 0.06 & - & - & - \\
\hline 12 & WET-2 & 0.594 & $t$ & 10.41 & -6.63 & 4.04 & - & - & - \\
\hline & & & $p$ & $<0.001$ & $<0.001$ & $<0.001$ & - & - & - \\
\hline & & & Value & 5.61 & -2.30 & 0.23 & - & -3.34 & - \\
\hline & & & Std. Dev. & 0.55 & 0.39 & 0.06 & - & 1.93 & - \\
\hline 13 & WET-2 & 0.608 & t & 10.29 & -5.85 & 4.15 & - & -1.73 & - \\
\hline & & & $p$ & $<0.001$ & $<0.001$ & $<0.001$ & - & 0.087 & - \\
\hline & & & Value & 5.73 & -2.51 & 0.22 & - & - & 5.42 \\
\hline & & & Std. Dev. & 0.56 & 0.38 & 0.06 & - & - & 23.34 \\
\hline 14 & WET-2 & 0.594 & $t$ & 10.29 & -6.59 & 3.69 & - & - & 0.23 \\
\hline & & & $p$ & $<0.001$ & $<0.001$ & $<0.001$ & - & - & 0.817 \\
\hline
\end{tabular}




\subsubsection{The Geonics EM38}

With a correlation coefficient of 0.45 the property correlated the most with the $\sigma_{\mathrm{e}}$ was the $\sigma_{\mathrm{b}}$. This was followed by the field water, the clay and the organic matter mass fractions (Table 9). Similarly to what happened with the SCT-10, the correlation with $\sigma_{\mathrm{e}}$ dropped to 0.43 when the temperature-standardized $\sigma_{\mathrm{b}, 25}$ was used instead of $\sigma_{\mathrm{b}}$.

Table 9. Pearson's product-moment correlation coefficients among the EM38 $\sigma_{\mathrm{b}}$ calculated values, and soil properties in the sites and depths the former were available.

\begin{tabular}{cccccc}
\hline & $\sigma_{\mathbf{b}}$ & $\sigma_{\mathbf{b}, 25}$ & $\sigma_{\mathbf{e}}$ & $w_{\mathbf{w}}$ & $w_{\mathbf{c}}$ \\
\hline$\sigma_{\mathbf{b}, 25}$ & 0.996 & & & & \\
$\sigma_{\mathbf{e}}$ & 0.451 & 0.434 & & & \\
$w_{\mathbf{w}}$ & 0.466 & 0.408 & 0.092 & & \\
$w_{\mathbf{c}}$ & 0.559 & 0.477 & -0.019 & 0.435 & \\
$w_{\text {om }}$ & -0.088 & -0.098 & 0.014 & 0.133 & 0.206 \\
\hline
\end{tabular}

In accordance with the calculated correlation coefficients, the properties $\sigma_{\mathrm{b}}, w_{\mathrm{w}}, w_{\mathrm{c}}$, and $w_{\mathrm{om}}$ were tried to be included in this order in an increasingly complex MLR for $\sigma_{\mathrm{e}}$ estimation with the EM38 instrument. The simple linear regression model using $\sigma_{\mathrm{b}}$ explained $20 \%$ of variance (Table 8 , model number 6 ). The inclusion of the field water mass fraction did not increase $\mathrm{R}^{2}$. This fact, along with a regression coefficient not different from zero at the $95 \%$ confidence level, made this property not be included in the eventual model for $\sigma_{\mathrm{e}}$ estimation (Table 8, model number 7). Contrary to this, the inclusion of the clay and the organic matter mass fractions did increase $\mathrm{R}^{2}$ and moreover, since their regression coefficients were different from zero at the $95 \%$ level, both were kept in a model of the form: $\sigma_{\mathrm{e}}=\mathrm{a} \sigma_{\mathrm{b}}+\mathrm{b} w_{\mathrm{c}}+\mathrm{c} w_{\text {om }}$ (Table 8 , model numbers 8 and 9). This last model explained $34 \%$ of variance and had RMSE of $2.1 \mathrm{dS} \mathrm{m}^{-1}(48 \%)$. The fit between predictions and measurements of $\sigma_{\mathrm{e}}$ according to model 9 can be appreciated in Figure 3b, which presents a Lin's concordance correlation coefficient equal to 0.50 .

\subsubsection{The Delta-T WET-2}

With a correlation coefficient of 0.55 , the property correlated the most with the $\sigma_{\mathrm{e}}$ was again the $\sigma_{\mathrm{b}}$, this was followed by the $\varepsilon_{b}{ }^{1 / 2}$, the temperature, the clay, and the organic matter mass fractions (Table 10). Interestingly again, the correlation with $\sigma_{\mathrm{e}}$ dropped to 0.53 when the temperature-standardized $\sigma_{\mathrm{b}, 25}$ was used instead of $\sigma_{\mathrm{b}}$.

Table 10. Pearson's product-moment correlation coefficients among the WET-2 probe measurements and calculations and soil properties in the sites and depths the former were available.

\begin{tabular}{cccccccccc}
\hline & $\sigma_{\mathbf{b}}$ & $\boldsymbol{T}$ & $\sigma_{\mathbf{b}, \mathbf{2 5}}$ & $\varepsilon_{\mathbf{b}}$ & $\sigma_{\mathbf{p}}$ & $\varepsilon_{\mathbf{b}}{ }^{1 / 2}$ & $\sigma_{\mathbf{e}}$ & $w_{\mathbf{w}}$ & $w_{\mathbf{c}}$ \\
\hline $\mathbf{T}$ & -0.166 & & & & & & & & \\
$\sigma_{\mathbf{b}, \mathbf{2 5}}$ & 0.995 & -0.241 & & & & & & & \\
$\boldsymbol{\varepsilon}_{\mathbf{b}}$ & 0.838 & -0.194 & 0.836 & & & & & & \\
$\sigma_{\mathbf{p}}$ & 0.904 & -0.222 & 0.907 & 0.607 & & & & & \\
$\varepsilon_{\mathbf{b}} \mathbf{1} / 2$ & 0.821 & -0.207 & 0.820 & 0.995 & 0.610 & & & & \\
$\sigma_{\mathbf{e}}$ & 0.551 & 0.180 & 0.525 & 0.187 & 0.705 & 0.199 & & & \\
$\boldsymbol{w}_{\mathbf{w}}$ & 0.641 & -0.216 & 0.639 & 0.822 & 0.419 & 0.825 & 0.078 & & \\
$\boldsymbol{w}_{\mathbf{c}}$ & 0.263 & -0.029 & 0.269 & 0.379 & 0.130 & 0.383 & -0.091 & 0.379 & \\
$\boldsymbol{w}_{\mathbf{o m}}$ & -0.181 & 0.363 & -0.209 & -0.113 & -0.283 & -0.113 & -0.023 & 0.139 & 0.266 \\
\hline
\end{tabular}

On the basis of the order found for the correlation coefficients, the properties $\sigma_{\mathfrak{b}}, \varepsilon_{\mathfrak{b}}{ }^{1 / 2}, T, w_{\mathrm{c}}$, and $w_{\text {om }}$ were tried to be included following this sequence in an increasingly complex MLR model for $\sigma_{\mathrm{e}}$ estimation with the WET-2 probe. The simple linear regression model using $\sigma_{\mathrm{b}}$ was able to explain $30 \%$ of variance (Table 8 , model number 10). The inclusion of $\varepsilon_{\mathbf{b}}{ }^{1 / 2}$, which was calculated from the WET-2 $\varepsilon_{\mathbf{b}}$ 
measurement, remarkably increased $\mathrm{R}^{2}$. This fact alongside a regression coefficient very significantly different from zero $(p<0.001)$ made this property be kept in the eventual model for $\sigma_{\mathrm{e}}$ estimation (Table 8, model number 11). The inclusion of the WET-2-measured temperature appreciably increased $\mathrm{R}^{2}$ again. Since the temperature had also a regression coefficient very significantly different from zero $(p<0.001)$, it was also kept in the model (Table 8, model number 12). Contrary to this, the inclusion of the mass fractions of either the clay or the organic matter did not noticeably increase $\mathrm{R}^{2}$ and moreover, their regression coefficients were not different from zero at the $95 \%$ confidence level (Table 8 , model numbers 13 and 14). As a consequence, these last two laboratory-determined properties were not included in the eventual model for $\sigma_{\mathrm{e}}$ estimation, and an equation of the form $\sigma_{\mathrm{e}}=\mathrm{a} \sigma_{\mathrm{b}}+\mathrm{b} \varepsilon_{\mathrm{b}}{ }^{1 / 2}+\mathrm{c} T$ could be accepted for the WET- 2 probe. This model explained $59 \%$ of variance and had RMSE of $1.7 \mathrm{dS} \mathrm{m}^{-1}(38 \%)$. The fit between predictions and measurements of $\sigma_{\mathrm{e}}$ according to the best most parsimonious model for the WET- $2 \sigma_{\mathfrak{b}}, \varepsilon_{\mathfrak{b}}{ }^{1 / 2}$ and $T$ data can be appreciated in Figure $3 c$, which features a Lin's concordance correlation coefficient equal to 0.74 .

In accordance with the correlation coefficients calculated between $\sigma_{\mathrm{e}}$ and the probe measurements and calculations, the $\sigma_{\mathrm{p}}$ given by Equation (12) was remarkably more correlated with $\sigma_{\mathrm{e}}(r=0.71)$ than whichever of the $\sigma_{\mathrm{b}}$ measurements $(0.45 \leq r \leq 0.55)$. Therefore, whether the use of $\sigma_{\mathrm{p}}$ instead of $\sigma_{\mathrm{b}}$ would improve the MLR model obtained for the WET- 2 was tested with the replacement of $\sigma_{\mathrm{b}}$ by $\sigma_{\mathrm{p}}$ in model 12 (Table 8). The model with the form $\sigma_{\mathrm{e}}=\mathrm{a} \sigma_{\mathrm{p}}+\mathrm{b} \varepsilon_{\mathrm{b}}{ }^{1 / 2}+\mathrm{c} T$ preserved all the regression coefficients significantly different from zero $(p<0.001)$, and was able to explain $69 \%$ of the variance in the $\sigma_{\mathrm{e}}$ data with a RMSE of $1.5 \mathrm{dS} \mathrm{m}^{-1}(33 \%)$. The fit between predictions and measurements of $\sigma_{\mathrm{e}}$ according to this model for the WET- $2 \sigma_{\mathrm{p}}, \varepsilon_{\mathrm{b}}{ }^{1 / 2}$ and $T$ data can be appreciated in Figure $3 \mathrm{~d}$, which presents a Lin's concordance correlation coefficient equal to 0.81 .

\section{Discussion}

Nowadays, soil scientists and practitioners have different techniques available for salinity appraisal by means of $\sigma_{\mathrm{b}}$ measurements. These techniques can be arranged in order of increasing complexity and hence age, from first to last: Electrical resistance (ER), electromagnetic induction (EMI), time domain reflectometry (TDR), and frequency domain reflectometry (FDR). In this work, three out of these four were compared, namely, ER, EMI, and FDR, by means of classical devices, respectively, the Martek SCT-10, the Geonics EM38, and the Delta-T WET-2. The $\sigma_{\mathrm{b}}$ measurements taken with all three instruments were moderate-to-highly correlated, however, not only scattering occurred, but also remarkable systematic deviations. These happened mainly between the SCT-10 probe and the other two because this ER sensor gave consistently higher $\sigma_{b}$ measurements.

In the case of the EM38, which is a contactless technique, the $\sigma_{\mathrm{b}}$ values were not measured but, alternatively, they had to be calculated by means of the inversion of Equation (6). This 1D inversion uses the sensitivity functions developed by McNeill [40], which were derived from an asymptotic approximation to the Maxwell's equations and are valid as long as the ability of the soil to attenuate the primary magnetic field of the EMI instrument is not too high. This occurs when the soils are not very conductive or, in other words, when the induction number is low enough $\left(N_{\mathrm{B}}<<1\right)$. According to different researches, the limit between low and high induction numbers $\left(N_{\mathrm{B}}\right)$ lays somewhere between 0.32 and 0.02 [53]. In our work, they have been estimated to be between 0.012 and 0.101 with mean of 0.055 , i.e., closer to the lower part of that range than to the higher one, thus giving us confidence that the low induction number hypothesis was acceptably fulfilled.

Therefore, assuming that the McNeill's approach to Maxwell's equations is acceptable for most of our soils, the $\sigma_{\mathrm{b}}$ values calculated by inversion of Equation (6) using Equations (4) and (5) are considered to adequately correspond to true $\sigma_{\mathrm{b}}$ values [53], i.e., those that would be measured by a reliable direct contact technique, e.g., either ER, FDR, or TDR. In our case, the dispersion between the EM38-calculated $\sigma_{\mathrm{b}}$ values and the WET- $2 \sigma_{\mathrm{b}}$ measurements can be attributed in an important extent to the very different soil volumes sensed by each probe as shown in Table 1, which was also a cause indicated by Coppola et al. [18] when comparing between EMI and TDR. However, in spite of this fact, 
on average, the EM38-calculated $\sigma_{\mathrm{b}}$ data were very similar to the WET-2 measurements thus boosting our confidence that the 1D inversion of Equation (6) had been appropriate.

The systematic departures in the SCT-10 measurements in comparison to the other two devices were even observed in the temperature. However, in spite of these differences all three instruments may still be profitably used for soil salinity appraisal provided probe-specific and maybe site-specific calibrations are developed. In this regard, modelling for $\sigma_{\mathrm{e}}$ estimation on the basis of only $\sigma_{\mathrm{b}}$ led to very poor models, mainly with the EM38 $\left(R^{2}=0.20\right)$, but also with the SCT-10 and the WET-2 probes $\left(R^{2}=0.30\right.$ both). Interestingly, the use of temperature-standardized measurements worsened the models. This fact indicates that an equation like Equation (2), which has been developed for aqueous solutions, does not satisfactorily work for the bulk soils. This is an already observed effect, which has been explained on the basis of the contribution to $\sigma_{\mathrm{b}}$ from the exchange ions within the bound soil water, whose conductivity would increase with temperature more steeply than the conductivity of the ions within the free soil water [54]. Therefore, since the soils of the study area are remarkably clayey, temperature should be included in the models for $\sigma_{\mathrm{e}}$ estimation, however, this must not be done with equations developed for aqueous systems, but through an alternative means. The inclusion of the temperature as another factor within an empirical MLR model was tried as this alternative in this research and it worked better, although significantly only for the WET-2 probe $(p<0.05)$.

Besides, since the $\sigma_{\mathrm{b}}$ is known to depend not only on salinity and temperature, but on several soil properties [9-12,14], other ground attributes were checked in the MLR models for $\sigma_{\mathrm{e}}$ estimation as has been done by other researchers [55]. These properties were selected considering the most influential on the $\sigma_{\mathrm{b}}{ }^{*}$ measurements taken with the EM38 (unpublished results): $w_{\mathrm{c}}, \theta_{\mathrm{w}}$, bulk density $\left(\varrho_{\mathrm{b}}\right), w_{\mathrm{om}}$, and $T$. Specifically, three of these properties were tried to be included as such since they had been either determined or measured $\left(w_{\mathrm{c}}, w_{\mathrm{om}}\right.$ and $\left.T\right)$, whereas for $\varrho_{\mathrm{b}}$ no data was available, and for $\theta_{\mathrm{w}}$ the inclusion was tried by means of surrogates, which were $\varepsilon_{\mathrm{b}}{ }^{1 / 2}$ in the case of the WET-2, and $w_{\mathrm{W}}$, in the case of the SCT-10 and the EM38.

Certainly, the inclusion of other soil properties for the estimation of the $\sigma_{\mathrm{e}}$ and thus salinity appraisal improved the prediction, giving rise to models with $\mathrm{R}^{2}$ and RMSE values of 0.44 and $1.8 \mathrm{dS} \mathrm{m}^{-1}, 0.34$ and $2.1 \mathrm{dS} \mathrm{m}^{-1}$, and 0.59 and $1.7 \mathrm{dS} \mathrm{m}^{-1}$ for, respectively, the SCT-10, the EM38, and the WET-2. Apparently, these model performance coefficients do not compare well with the ones obtained in other works, e.g., Zemni et al. [34] achieved RMSE values below $1 \mathrm{dS} \mathrm{m}^{-1}$ for a CCC probe, and Samson et al. [22] $\mathrm{R}^{2}$ up to 0.98 for CCC and TDR probes. However, compared to theirs and other researchers', the testing conditions of the study area in this work were very challenging because of its large extension and thus diversity of soils. This fact contrasts with the conditions of the aforementioned studies in which only one sandy soil was tested. Besides, in this work, the estimation of $\sigma_{\mathrm{e}}$ was tried, whereas in the aforesaid and most others' the easier $\sigma_{\mathrm{p}}$ is tried. In any case, in this work, the use of $\theta_{\mathrm{w}}$ instead of $w_{\mathrm{w}}$ and the additional use of $\varrho_{\mathrm{b}}$ would have improved the models. Besides, the use of soil samples more representative of the actual soil volume sensed by the EM38 would have decreased the scattering of predicted against observed $\sigma_{\mathrm{e}}$ and hence increased $\mathrm{R}^{2}$ and decreased RMSE. Finally, the use of different model approaches would have maybe improved a bit more the models' prediction ability. Nevertheless, the development of the best possible model for each probe was not the objective of this investigation, but a means to compare among them.

Therefore, what it is interesting is to note that, whatever the case, in order to attain better estimation performances, the soil must be drilled regardless of the instrument that is used, even with the contactless EM38. Additionally, samples should be separately taken from different soil depth intervals and analyzed in the laboratory for field water and clay mass fractions in the case of the SCT-10, and for clay and organic matter mass fractions in the case of the EM38, but not in the case of the WET-2. This way of working overshadows some of the benefits of using sensors in the case of the SCT-10 and even more the EM38. On the contrary, in the case of the WET-2, only probe measurements were needed to develop an MLR model for $\sigma_{\mathrm{e}}$ estimation and therefore for salinity appraisal on the basis of $\sigma_{\mathrm{b}}$. The use of the sensor-calculated $\sigma_{\mathrm{p}}$ instead of the sensor-measured $\sigma_{\mathrm{b}}$ further improved the $\sigma_{\mathrm{e}}$ 
estimation reaching a $\mathrm{R}^{2}$ of 0.69 . However, the RMSE was still $1.5 \mathrm{dS} \mathrm{m}^{-1}$, which is somewhat far from satisfactory since the amplitude interval of the lower classes of salt affected soils is $2 \mathrm{dS} \mathrm{m}^{-1}$ (Table 11).

Given that working at higher frequencies is known to attenuate the effects of soil type, $\sigma_{\mathrm{b}}$ and $T$ on the $\varepsilon_{\mathrm{b}}$ measurement [56], the use of frequencies over $20 \mathrm{MHz}$ in WET-2-like FDR and TDR sensors such as the CS655 (Campbell Scientific, Inc., Logan, UT, USA), which uses two frequencies of $175 \mathrm{MHz}$ and $100 \mathrm{MHz}$ in order to better characterize $\sigma_{\mathrm{b}}$ and thus refine the $\varepsilon_{\mathrm{b}}$ measurement [57], is expected to enhance the soil salinity appraisal with the aim of diminishing the RMSE down to more acceptable values while keep using only sensor data.

Table 11. Soil salinity assessment scheme for agriculture based on the threshold-slope model of crop yield decline. Re-elaborated from Richards et al. [58] and Ayers and Westcot [59].

\begin{tabular}{|c|c|c|c|}
\hline${ }^{\dagger} \sigma_{\text {et }} / \mathrm{dS} \mathbf{m}^{-1}$ & Salt Affected Crops & ${ }^{\dagger} \sigma_{\text {ea }} / \mathrm{dS} \mathrm{m}^{-1}$ & Soil Salinity Class \\
\hline$<1.3$ & Sensitive & $<2$ & Non saline \\
\hline$[1.3,3)$ & Moderately sensitive & {$[2,4)$} & Slightly saline \\
\hline$[3,6)$ & Moderately tolerant & {$[4,8)$} & Moderately saline \\
\hline$[6,10)$ & Tolerant & {$[8,16)$} & Strongly saline \\
\hline$\geq 10$ & Halophytes & $\geq 16$ & Extremely saline \\
\hline
\end{tabular}

${ }^{\dagger} \sigma_{\text {et }}$ : Soil saturation extract electrical conductivity at $25^{\circ} \mathrm{C}$, over which yield starts to decline; $\sigma_{\text {ea }} ;$ Soil saturation extract electrical conductivity at $25^{\circ} \mathrm{C}$, over which yield drops below $90 \%$ of maximum for all classes except for the last one, for which it drops below $70 \%$ of maximum.

\section{Conclusions}

The field comparison made between three classical commercial devices capable of EC detection, each one featuring a different physical foundation, i.e., ER, EMI, and FDR, revealed several interesting things related to the evolution the technology for field soil salinity appraisal has witnessed in the past forty years. The comparison has shown, first of all, that the use of one specific device determines the way of working not only because of the physical foundation of the $\sigma_{b}$ measurement, but also because of the add-ons the specific devices include. These extra features can be additional measurements such as temperature, which is naturally and easily integrated with the aid of a built-in thermistor alongside contact techniques like ER (SCT-10) and FDR (WET-2), and relative dielectric permittivity, which can only be implemented in FDR and TDR technologies or integrated with the aid of the two-electrode ER technique in combined probes such as the modern capacitance-conductance (CCC) ones. These extra features can also be additional calculations such as the temperature-standardized $\sigma_{\mathrm{b}, 25}$, as well as $\theta_{\mathrm{w}}$ and $\sigma_{\mathrm{p}}$ in FDR and TDR or CCC. Regarding temperature, it has been also shown that the evolution of temperature in aqueous solutions does not represent the evolution in bulk soils and that an alternative should be chosen, e.g., another factor in the framework of an MLR model. Finally, in this work it has been shown that an FDR contact probe like the WET- 2 not only provided the best estimation model making use of the additional $\sigma_{\mathrm{p}}$ calculation, but also provided a balance between labor and information obtained because, even though with this contact device soil drilling is necessary to access the subsoil layers, it is also the only one in which soil sampling and laboratory analysis are not needed at all to develop a $\sigma_{\mathrm{e}}$ estimation model. The ongoing development of light weight non expensive FDR and TDR probes, specifically working at higher frequencies for enhanced $\varepsilon_{\mathrm{b}}$ and $\sigma_{\mathrm{b}}$ estimations, offers a promising way in which salinity appraisal is going to improve and made available for a greater audience. In the future, similar comparisons will be made, including the most recent commercial TDR and CCC probes.

Author Contributions: F.V.: Conceptualization, methodology, software, validation, formal analysis, investigation, data curation, writing-original draft, writing-review \& editing, visualization; J.M.d.P.: Conceptualization, methodology, formal analysis, investigation, resources, writing — original draft, writing — review \& editing, supervision, project administration, funding acquisition. All authors have read and agreed to the published version of the manuscript. 
Funding: The survey of this project was carried out within project GV 0461/2006, funded by the Generalitat Valenciana.

Conflicts of Interest: The authors declare no conflict of interest.

\section{References}

1. Metternicht, G.I.; Zinck, J.A. Remote sensing of soil salinity: Potentials and constraints. Remote Sens. Environ. 2003, 85, 1-20. [CrossRef]

2. Tanji, K.K.; Wallender, W.W. Nature and extent of agricultural salinity and sodicity. In Agricultural Salinity Assessment and Management, 2nd ed.; Wallender, W.W., Tanji, K.K., Eds.; ASCE: Reston, VA, USA; EWRI: Reston, VA, USA, 2012; pp. 1-25. [CrossRef]

3. AQUASTAT: FAO's Information System on Water and Agriculture. Available online: http://www.fao.org/nr/ water/aquastat/catalogues/index.stm (accessed on 19 February 2019).

4. Dasgupta, S.; Hossain, M.M.; Huq, M.; Wheeler, D. Climate change and soil salinity: The case of coastal Bangladesh. AMBIO 2015, 44, 815-826. [CrossRef] [PubMed]

5. De Paz, J.M.; Visconti, F.; Molina, M.J.; Sánchez, J.; Martínez, D.; Jiménez, G. Prediction of the effects of climate change on the soil salinity of an irrigated area under Mediterranean conditions. In Proceedings of the 4th International Congress EUROSOIL 2012, Bari, Italy, 2-6 July 2012; p. 1572.

6. Maas, E.V.; Hoffman, G.J. Crop salt tolerance- current assessment. J. Irrig. Drain. Div. 1977, 103, 115-134.

7. Maas, E.V. Salinity and citriculture. Tree Physiol. 1993, 12, 195-216. [CrossRef]

8. Shannon, M.C.; Grieve, C.M. Tolerance of vegetable crops to salinity. Sci. Hortic. 1999, 78, 5-38. [CrossRef]

9. Rhoades, J.D.; Lesch, S.M.; Shouse, P.J.; Alves, W.J. New calibrations for determining soil electrical conductivity-depth relations from electromagnetic measurements. Soil Sci. Soc. Am. J. 1989, 53, 74-79. [CrossRef]

10. Mualem, Y.; Friedman, S.P. Theoretical prediction of electrical conductivity in saturated and unsaturated soil. Water Resour. Res. 1991, 27, 2771-2777. [CrossRef]

11. Friedman, S.P. Soil properties influencing apparent electrical conductivity: A review. Comput. Electron. Agric. 2005, 46, 45-70. [CrossRef]

12. Corwin, D.L.; Lesch, S.M. Apparent soil electrical conductivity measurements in agriculture. Comput. Electron. Agric. 2005, 46, 11-43. [CrossRef]

13. Kelleners, T.J.; Verna, A.K. Measured and modelled dielectric properties of soil at 50 Megahertz. Soil Sci. Soc. Am. J. 2010, 74, 744-752. [CrossRef]

14. Visconti, F.; de Paz, J.M. A semi-empirical model to predict the EM38 electromagnetic induction measurements of soils from basic ground properties. Eur. J. Soil Sci. 2020, 1-19. [CrossRef]

15. Corwin, D.L.; Rhoades, J.D. Establishing soil electrical conductivity-Depth relations from electromagnetic induction measurements. Commun. Soil Sci. Plan. 1990, 21, 861-901. [CrossRef]

16. Johnston, M.A.; Savage, M.J.; Moolman, J.H.; du Plessis, H.M. Evaluation of calibration methods for interpreting soil salilinity from electromagnetic induction measurements. Soil Sci. Soc. Am. J. 1997, 61, 1627-1633. [CrossRef]

17. Wittler, J.M.; Cardon, G.E.; Gates, T.K.; Cooper, C.A.; Sutherland, P.L. Calibration of electromagnetic induction for regional assessment of soil water salinity in an irrigated valley. J. Irrig. Drain. Eng. 2006, 132, 436-444. [CrossRef]

18. Coppola, A.; Smettem, K.; Ajeel, A.; Saeed, A.; Dragonetti, G.; Comegna, A.; Lamaddalena, N.; Vacca, A. Calibration of an electromagnetic induction sensor with time-domain reflectometry data to monitor rootzone electrical conductivity under saline water irrigation. Eur. J. Soil Sci. 2016, 67, 737-748. [CrossRef]

19. Rhoades, J.D.; van Schilfgaarde, J. An electrical conductivity probe for determining soil salinity. Soil Sci. Soc. Am. J. 1976, 40, 647-651. [CrossRef]

20. Kizito, F.; Campbell, C.S.; Campbell, G.S.; Cobos, D.R.; Teare, B.L.; Carter, B.; Hopmans, J.W. Frequency, electrical conductivity and temperature analysis of a low-cost capacitance soil moisture sensor. J. Hydrol. 2008, 352, 367-378. [CrossRef]

21. Visconti, F.; Martínez, D.; Molina, M.J.; Ingelmo, F.; De Paz, J.M. A combined equation to estimate the soil pore water electrical conductivity: Calibration with the WET and 5TE sensors. Soil Res. 2014, 52, 419-430. [CrossRef] 
22. Samson, M.E.; Caron, J.; Pepin, S.; Parys, B.; Fortin, J. Precision and accuracy of time-domain reflectometry and capacitive probes to determine soil electrical conductivity in cranberry production-Technical note. Can. J. Soil Sci. 2017, 97, 31-37. [CrossRef]

23. Malicki, M.; Walczak, R.; Koch, S.; Fluhler, H. Determining soil salinity from simultaneous readings of its electrical conductivity and permittivity using TDR. In Proceedings of the Symposium on Time Domain Reflectometry in Environmental, Infrastructures and Mining Applications, U.S. Bureau of Mines, Evanston, IL, USA, 7-9 September 1994; pp. 328-336.

24. Noborio, K. Measurement of soil water content and electrical conductivity by time domain reflectometry: A review. Comput. Electron. Agric. 2001, 31, 213-237. [CrossRef]

25. Doolittle, J.A.; Brevik, E.C. The use of electromagnetic induction techniques in soils studies. Geoderma 2014, 223, 33-45. [CrossRef]

26. Visconti, F.; De Paz, J.M. Electrical conductivity measurements in agriculture: The assessment of soil salinity. In New Trends and Developments in Metrology; Cocco, L., Ed.; Intech: Rijeka, Croatia, 2016; pp. 99-126.

27. Lesch, S.M.; Herrero, J.; Rhoades, J.D. Monitoring for temporal changes in soil salinity using electromagnetic induction techniques. Soil Sci. Soc. Am. J. 1998, 62, 232-242. [CrossRef]

28. Yao, R.; Yang, J. Quantitative evaluation of soil salinity and its spatial distribution using electromagnetic induction method. Agric. Water Manag. 2010, 97, 1961-1970. [CrossRef]

29. Taghizadeh-Mehrjardi, R.; Minasny, B.; Sarmadianc, F.; Malone, B.P. Digital mapping of soil salinity in Ardakan region, central Iran. Geoderma 2014, 213, 15-28. [CrossRef]

30. Dakak, H.; Huang, J.; Zouahri, A.; Douaik, A.; Triantafilis, J. Mapping soil salinity in 3-dimensions using an EM38 and EMSoil inversion modelling at the reconnaissance scale in central Morocco. Soil Use Manag. 2017, 33, 553-567. [CrossRef]

31. Hilhorst, M.A. A pore water conductivity sensor. Soil Sci. Soc. Am. J. 2000, 64, 1922-1925. [CrossRef]

32. Buss, P.; Dalton, M.; Green, S.; Guy, R.; Roberts, C.; Gatto, R.; Levy, G. Use of TriSCAN for measurement of water and salinity in the soil profile. Engineering Salinity Solutions. In Proceedings of the 1st National Salinity Engineering Conference 2004, Engineers Australia, Barton, ACT, Australia, 9-12 November 2004; pp. $206-211$.

33. Wilczek, A.; Szyplowska, A.; Skierucha, W.; Ciesla, J.; Pichler, V.; Janik, G. Determination of soil pore water salinity using an FDR sensor working at various frequencies up to $500 \mathrm{MHz}$. Sensors 2012, 12, 10890-10905. [CrossRef]

34. Zemni, N.; Bouksila, F.; Persson, M.; Slama, F.; Berndtsson, R.; Bouhlila, R. Laboratory calibration and field validation of soil water content and salinity measurements using the 5TE sensor. Sensors 2019, 19, 5272. [CrossRef]

35. Hamed, Y.; Samy, G.; Person, M. Evaluation of the WET sensor compared to time domain reflectometry. Hydrol. Sci. J. 2006, 51, 671-681. [CrossRef]

36. Dragonetti, G.; Comegna, A.; Ajeel, A.; Piero Deidda, G.; Lamaddalena, N.; Rodriguez, G.; Vignoli, G.; Coppola, A. Calibrating electromagnetic induction conductivities with time-domain reflectometry measurements. Hydrol. Earth Syst. Sci. 2018, 22, 1509-1523. [CrossRef]

37. Rhoades, J.D.; Chanduvi, F.; Lesch, S. Soil Salinity Assessment: Methods and Interpretation of Electrical Conductivity Measurements; FAO Irrigation and Drainage: Rome, Italy, 1999.

38. Martek Instruments. Instruction Manual Model SCT; Martek Instruments Inc.: Irvine, CA, USA, 1982.

39. Ma, R.; McBratney, A.; Whelan, B.; Minasny, B.; Short, M. Comparing temperature correction models for soil electrical conductivity measurement. Precis. Agric. 2011, 12, 55-66. [CrossRef]

40. McNeill, J.D. Electromagnetic Terrain Conductivity Measurement at Low Induction Numbers. In Tech. Note TN-6; Geonics Pty Ltd.: Mississauga, ON, Canada, 1980.

41. Borchers, B.; Uram, T.; Hendrickx, J.M.H. Tikhonov regularization of electrical conductivity depth profiles in field soils. Soil Sci. Soc. Am. J. 1997, 61, 1004-1009. [CrossRef]

42. Hendrickx, J.M.H.; Borchers, B.; Corwin, D.L.; Lesch, S.M.; Hilgendorf, C.; Schlue, J. Inversion of soil conductivity profiles from electromagnetic induction measurements theory and experimental verification. Soil Sci. Soc. Am. J. 2002, 66, 673-685.

43. Delta-T Devices. User Manual for the WET Sensor; Delta-T Devices Ltd.: Cambridge, UK, 2007.

44. Kaatze, U.; Uhlendorf, V. The dielectric properties of water at microwave frequencies. Z. Phys. Chem. 1981, 126, 151-165. [CrossRef] 
45. De Paz, J.M.; Visconti, F.; Zapata, R.; Sánchez, J. Integration of two simple models in a geographical information system to evaluate salinization risk in irrigated land of the Valencian Community, Spain. Soil Use Manag. 2004, 20, 333-342. [CrossRef]

46. de Paz, J.M.; Visconti, F.; Rubio, J.L. Spatial evaluation of soil salinity using the W.E.T. sensor in the irrigated area of the Segura river lowland. J. Plant Nutr. Soil Sci. 2011, 174, 103-112. [CrossRef]

47. Rhoades, J.D. Salinity: Electrical conductivity and total dissolved solids. In Methods of Soil Analysis Part 3-Chemical Methods; Sparks, D.L., Page, A.L., Helmke, P.A., Loeppert, R.H., Soltanpour, P.N., Tabatabai, M.A., Johnston, C.T., Sumner, M.E., Eds.; SSSA: Madison, WI, USA; ASA: Madison, WI, USA, 1996; pp. 417-435.

48. Gee, G.W.; Or, D. Particle-size analysis. In Methods of Soil Analysis. Part 4. Physical Methods; Campbell, G., Horton, R., Jury, W.A., Nielsen, D.R., van Es, H.M., Wierenga, P.J., Dane, J.H., Topp, G.C., Eds.; SSSA: Madison, WI, USA; ASA: Madison, WI, USA, 2002; pp. 255-294.

49. Nelson, D.W.; Sommers, L.E. Total carbon, organic carbon and organic matter. In Methods of Soil Analysis Part 3-Chemical Methods; Sparks, D.L., Page, A.L., Helmke, P.A., Loeppert, R.H., Soltanpour, P.N., Tabatabai, M.A., Johnston, C.T., Summer, M.E., Eds.; SSSA: Madison, WI, USA; ASA: Madison, WI, USA, 1996; pp. 961-1010.

50. Visconti, F.; De Paz, J.M.; Rubio, J.L. An empirical equation to calculate soil solution electrical conductivity at $25{ }^{\circ} \mathrm{C}$ from major ion concentrations. Eur. J. Soil Sci. 2010, 61, 980-993. [CrossRef]

51. Lin, L. A concordance correlation coefficient to evaluate reproducibility. Biometrics 1989, 45, $255-268$. [CrossRef] [PubMed]

52. R Core Team. R: A Language and Environment for Statistical Computing; R Foundation for Statistical Computing: Vienna, Austria, 2017; Available online: https://www.project.org (accessed on 17 September 2017).

53. Callegary, J.B.; Ferré, T.P.A.; Groom, R.W. Vertical spatial sensitivity and exploration depth of low-induction-number electromagnetic-induction instruments. Vadose Zone J. 2007, 6, 158-167. [CrossRef]

54. Wraith, J.M.; Or, D. Temperature effects on soil bulk dielectric permittivity measured by time domain reflectometry: Experimental evidence and hypothesis. Water Resour. Res. 1999, 35, 361-369. [CrossRef]

55. Brevik, E.C.; Fenton, T.E. Influence of soil water content, clay, temperature, and carbonate minerals on electrical conductivity readings taken with an EM-38. Soil Survey Horiz. Spring 2002, 43, 9-13. [CrossRef]

56. Campbell, J.E. Dielectric properties and influence of ionic conductivity in soils at one to fifty megahertz. Soil Sci. Soc. Am. J. 1990, 54, 332-341. [CrossRef]

57. Caldwell, T.G.; Bongiovanni, T.; Cosh, M.H.; Halley, C.; Young, M.H. Field and laboratory evaluation of the CS655 soil water content sensor. Vadose Zone J. 2018, 17, 170214. [CrossRef]

58. Richards, L.A.; Allison, L.E.; Bernstein, L.; Bower, C.A.; Brown, J.W.; Fireman, M.; Hatcher, J.T.; Hayward, H.E.; Pearson, G.A.; Reeve, R.C.; et al. Diagnosis and Improvement of Saline and Alkali Soils; United States Department of Agriculture: Madison, WI, USA, 1954.

59. Ayers, R.S.; Westcot, D.W. Water Quality for Agriculture; Food and Agriculture Organization of the United Nations: Rome, Italy, 1985.

(C) 2020 by the authors. Licensee MDPI, Basel, Switzerland. This article is an open access article distributed under the terms and conditions of the Creative Commons Attribution (CC BY) license (http://creativecommons.org/licenses/by/4.0/). 